DE DE GRUYTER

OPEN

G

BULGARIAN ACADEMY OF SCIENCES

CYBERNETICS AND INFORMATION TECHNOLOGIES • Volume 16, No 3

Sofia $2016 \quad$ Print ISSN: 1311-9702; Online ISSN: 1314-4081

DOI: $10.1515 /$ cait-2016-0032

\title{
Adaptation in Affective Video Games: A Literature Review
}

\section{Boyan Bontchev}

Software Engineering, Sofia University "St. Kliment Ohridski”, 1000 Sofia, Bulgaria Marie Curie Fellow at Brainstorm Multimedia, Valencia, Spain

Email: bbontchev@fmi.uni-sofia.bg

\begin{abstract}
Playing computer games is a predominantly emotional than rational process. Video games with affect-based adaptation measure player's behavior signals and recognize player's emotional states in order to adapt specific game features in a dynamic manner and to improve player's engagement, immersion, excitement, and challenge. The present review deals with models for the presentation of emotions, techniques for measuring behavioral signals, emotion recognition and adaptation mechanisms applied in video games with affective feedback including methods for their assessment and validation. Studies using self-reports, observational methods and psychophysiological measurements of both autonomic and central nervous systems including processing and interpretation of signals are systematically reviewed with regard to their results concerning emotional adaptation in games. Next, the article provides a comparative analysis of affect-based adaptation methods and techniques applied in 14 adaptive video games developed in last ten years. Based on this comparison, we summarized future directions in research, design and evaluation of video games with affective adaption.
\end{abstract}

Keywords: Video games, affective feedback, adaptation, emotion.

\section{Introduction}

The term affective computing was proposed by $\mathrm{Pic}$ ard [1] as a type of computing that "relates to, arises from, or influences emotions". In the past 20 years, a plea for novel, emotionally intelligent systems and applications was proposed, based on affective computing models for recognition, processing, interpretation, visualization, simulation and stimulation of affective experiences [2]. With the evolution of affective systems, biofeedback [3] gained popularity with various methods of obtaining users' awareness of certain aspects of individual physiological reactions to physical and/or psychic stress. Next to biofeedback, B e rs a k et al. [4] coined the term affective feedback by imposing the idea for "an active intelligent participant in the biofeedback loop". More precisely, affective feedback was defined as direct biofeedback influencing the user not only by information about his/her personal 
"bio-state" but mostly by the way of its presentation. In fact, affective feedback was used earlier by Pope, Bogart, and Bartolome [5] in order to detect negative emotional states by measuring electroencephalographic signals and, next, to select specific features for calculating an index of operator engagement used to make decisions how to reconfigure automated tasks. Besides measuring activity of the Central Nervous System (CNS) by using electroencephalography [6] or other brain imaging technologies [7], biofeedback systems register changes in signals produced by the Autonomic Nervous System (ANS) such as heart rate variability, blood pressure, and skin conductance response. For a detailed review of ANS measures [8].

Modern affective feedback computing systems move the focus of applying information about user affect from adapted task automation to dynamic adjustment of game difficulty level [9] and adaptation of audio-visual effects [10]. Among the variety of affective feedback systems, affective 3D visual spaces and video games gained ever growing popularity worldwide by engaging players in emotionally intensive interactions [11]. Affective feedback design was used in both entertainment video games and serious games specially dedicated to education, training, and rehabilitation therapies [12]. Gilleade, Dix and Allans on [13] defined affective gaming as a specific form of gameplay "where the player's current emotional state is used to manipulate gameplay". Affective 3D visual spaces and player-centered video games rely on specific design of the environment in order to affect the user's mental state and to adjust some system features according to the induced affect. They appeal to users by rewarding them for moving to desired psychophysiological states and, thus, create more dynamic and unpredictable gameplay and generate personalized and situated game experiences [14].

Affective video games measure physiological signals and use them for recognizing player's emotional states for enabling more spectacular and exciting forms of gameplay [15]. Emotion-based games are reported to improve player's engagement, immersion, excitement, and challenge $[16,17]$ by dynamically adapting specific game features according to the recognized emotions or directly to the measured physiological signals within a feedback loop [18]. Yannakakis and Tigelius [19] define three basic system requirements for a successful implementation of the affective loop within adaptive games: (1) tailoring emotionally-adaptive games to affective response patterns of each individual player; (2) implicit to players adaptation process at run time; and (3) affect-based interactions should match game context, adaptable game features, individual subjective input, and objective data obtained from alternative player modalities.

Emotionally-based adaptation is capable of inducing desired emotional player states such as excitement or engagement and, at the same time, to avoid other, undesired states like boredom or overload [20] Affective video games with emotionbased adaptation use three types of mechanisms for dynamic adaptation during the gameplay, namely:

- adjustment of explicit, implicit, or player-driven game tasks [21] and their managed appearance in the game flow [22];

- adaptation of difficulty towards player's anxiety [23] or skill level [20];

- adjustment of audio-visual properties such as ambient light [24]. 
There are several detailed reviews in the area of adaptive games presenting stateof-the-art experience-driven procedural content generation [19], personalized gaming in general [25], adaptive serious games for education [26], and dynamic difficulty adjustment in computer games [27]. Other reviews discuss affective games concerning mainly fundamentals of physiological computing [28], psychophysiological methods in game research [15], methods for data fusion and system adaptation using ANS responses [29], and a historical view of technological advancements in affective gaming [30]. In contrast to them, the present article provides a review on adaptation models, mechanisms and practices used in affective video games including ways of their application, assessment and experimental validation. Section 2 presents fundamentals of affective feedback and its application in affective games. The targets of adaptation are discussed, i.e. gaming features adapted according to recognized player's affective states via a physiology-based methods for affect inference. Section 3 is dedicated to the player representation in adaptive affective games, required for detecting changes in the emotional state of human players. There are both discrete and dimensional modelling perspectives of studying emotions. Next, flow, immersion and motivation are introduced as psychological concepts important for effective design and evaluation of affective games. Section 4 discusses measuring and recognizing emotions in player-centric adaptive games. Self-reports, observational methods and psychophysiological measurements are analysed with regards to their advantages and disadvantages as emotion measurement strategies. There is a discussion regarding the types of measurements of physiological signals produced by ANS and CNS, which are highly used in affective games. Both processing and interpretation of physiological signals are outlined with respect of their use for emotion recognition. Section 5 provides a discussion about adaptation in modern affective games. 14 video games with affectbased adaptation developed in last ten years are analysed and compared according various criteria concerning properties of affective video games, technological and methodological issues of game realisation and, as well, experimental validation, outcomes and impact of the affect-based adaptation. Finally, the conclusions demarcate directions in research, design and evaluation of future adaptive affective video games (Section 6).

\section{Affective adaptation in video games}

Since the time of their advent, video games apply adaptive techniques according to data about player's performance. Player-centric adaptive gameplay possesses essential advantages compared to the static, non-adaptive gameplay, as far as an appropriately adaptive game succeeds in matching essential cognitive features of the player. They increase stepwise game difficulty level according to player's results and skills demonstrated during gameplay. However, playing a game is mainly an emotional process and, therefore, adaptation based on player performance is not sufficient in terms to adjust the game features to goals, preferences, emotions and expectations of each individual player. R ou se [31] formulates the central problem of computer games regarding their highly interactive nature as a necessity to 
"give players the power to make their own choices, decisions which effect which emotions they may feel immediately or later in the game". This makes emotionallybased adaptation methods used in affective games especially significant, as they deal with dynamic game balancing in order to adjust specific game elements and parameters in an appropriate way.

\subsection{Application of affective feedback in video games}

Traditional biofeedback defines a standard biofeedback loop, where users learn to control their physiological state based on information provided by bio-sensors and presented on a device or a given media. On other hand, as stated by B e r s a k et al. [4] computers should have "the ability to recognize, react to, and affect our physiological state in a meaningful way". The authors created a racing game called Relax-to-Win and using player's galvanic skin responses for measuring current level of relaxation of given player and, next, controlling the speed of a dragon within the gameplay according to this relaxation's level. Therefore, they demonstrated the so called affective feedback loop where the computer (but not the user) learns how environments affect the psycho-physiological user's state and adjusts its behaviour according to these changes. The users start feeling more and more involved in the process, while their emotions are reinforced. The affective loop does not represent how the system infers users' emotional states, however, for reacting appropriately to the communicated emotional expressions, the systems has either to classify or to estimate the physiological responses received from the users [29].

Gilleade, Dix and Allanson [13] defined affective game as a game supporting the affective feedback loop, which differs from the standard biofeedback loop in terms of propagation of uncontrolled affective information. As they noted if, after sufficient practicing the game, players becomes skilful enough to control their normal physiological responses, then this awareness of volitional control will convert the affective game into a game with "straight-forward biofeedback". Such biofeedback games are defined by $\mathrm{Nacke}$ et al. [32] as games with "direct physiological control" meaning direct (voluntary) manipulation and control of actions in the virtual world by the player using muscle flexion, eye gaze or input from temperature sensor (through blowing hot air on it). In contrast, indirectly-controlled physiological games are manipulated in an indirect (involuntary) by player's body activations such as heart rate and galvanic skin response. The direct-indirect dichotomy of physiological control is similar to the approach of $\mathrm{Ku} \mathrm{i} \mathrm{k} \mathrm{ka} \mathrm{ni} \mathrm{e} \mathrm{mi} \mathrm{et}$ al. [33] who applied both implicit and explicit biofeedback mechanisms within a First-Person Shooter (FPS) game. They used explicit for the player control over game dynamics making him/her aware about game manipulation, which resulted in increasing player's immersion, while the implicit control was based on player's physiological state without players to be conscious about the changes.

A more precise processing model of player-centric adaptation in affective video games is proposed by Parnandi and Gutierrez-Osuna [34] based on concepts from classical control theory. The model shows how a game parameter (e.g., game difficulty level) is controlled by the level of player's arousal estimated by measuring a physiological response (Electro-Dermal Activity, or EDA) of the player. 
By using the affective loop (Fig. 1), the model tries to keep the value of EDA measured at time $t$ (indicated as $r(t)$ ), i.e., current player's arousal, at an optimal setpoint level (denoted as $r_{0}$ in the figure); $s(t)$ stands for game stimuli level (e.g., game difficulty level) in time $t$ and is used as emotional stimulus for the player, and $\epsilon(t)$ is the error presenting the difference between value of EDA during time $t$ and the chosen set-point level.

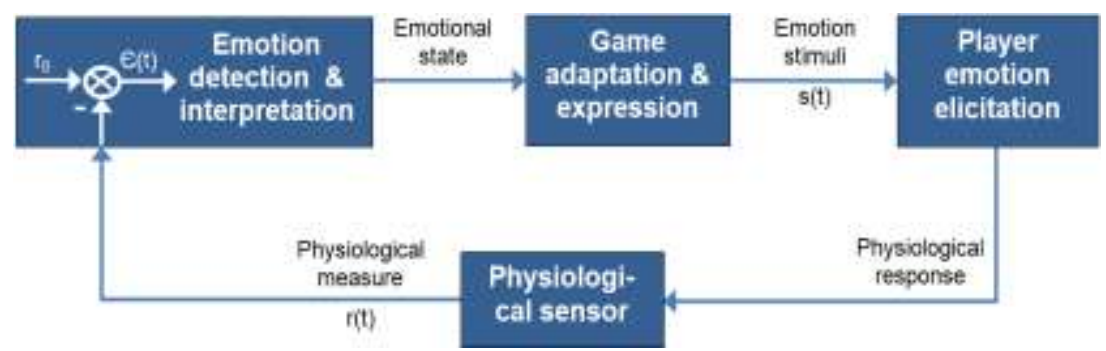

Fig. 1. Block-diagram of an adaptive affective game [34]

This adaptive scheme shown in Fig. 1 uses a negative feedback control - it keeps player's arousal near the optimal level to offer improved player's attention and therefore higher performance during the game play. In this way, negative control loops reduce the difference (the error) between the real-time psychophysiological measure and the desired level (standard) of player's emotional state and, thus, create behavioural stability during gameplay by keeping the player within a safe zone of stability of performance effectiveness [28]. Contrary to the negative feedback, positive physiological feedback control is discrepancy-enlarging and acts as an amplifier of the difference between the measured psychophysiological input and the desired player's standard one, leading to performance instability. When applying positive feedback control, the biocybernetic system may steadily increase the desired level of player's emotion, for reaching greater performance and pleasure thanks to elicited creative impulses [35]. Within combined scenarios, the affective feedback loop may toggle between positive and negative control dynamics [28], where positive feedback used for relatively shorter gameplay aiming at skill acquisition is alternated with longer time intervals of "performance stability and skill consolidation" possible only under negative feedback control.

\subsection{Targets of affective adaptation in video games}

Affective loop explains how game adaptation creates emotion stimuli resulting in emotion elicitation from the player. Therefore, it is crucially important to outline possible targets of adaptation in affective game design, which elicit player's emotions and hence evoke physiological responses. As real-time physiological responses vary between players with different profiles regarding their gaming experiences and affective personality traits, Gilleade, Dix and Allans on [13] proposed a vertical approach to the classification of the targets of game adaptation consisting of three high-level design heuristics for dynamic adjustment of affective gaming: "assist me-challenge me-emote me". Players might be assisted at any problematic situations during the gameplay, for example such with rising frustration measured by the game 
[36], or by using adaptive companions changing their behaviour - between cautious, supporting and aggressive one - according to player's experience for reaching more meaningful and engaging gameplay [37]. The challenge me heuristic represents base for research in adaptive games concerning Dynamic Difficulty Adjustment (DDA) instead simple increasing of difficulty level, for balancing game challenge according player's skills [38]. The last heuristic (emote me) is only sketched in [13], however, it reveals a great potential to provoke desired emotions by changing design aesthetics and multimedia content of a video game based on actual emotions of the player. In such biofeedback-controlled games and environments, player's emotions are detected through physiological signals and used further for controlling some audio-visual aspects of the game, like adapting game sound for supporting greater player's immersion and sense of presence [39].

The "assist me-challenge me-emote me" game design model corresponds semantically to other design triangles proposed in other researchers and game developers. The most distinguished of them is probably the MDA (standing for Mechanics, Dynamics, and Aesthetics) paradigm coined by Hunicke and $\mathrm{Ch}$ a p m an [40], where mechanics stand for game formal rules, their enforcement mechanisms, data representation and algorithms embedded within game components; dynamics describe the run-time behaviour of the mechanics; and aesthetics present emotional responses evoked in players by the dynamics like excitement, frustration or motivational intensity. On the other hand, MDA levels are mapped clearly to three main categories of game adaptation summarized by $\mathrm{Novak}, \mathrm{Mihelj}$ and $\mathrm{Munih}$ [29] as: (1) adaptive automation of tasks with possible provision of automated assistance; (2) adjustment of game difficulty level (often abbreviated as DDA from dynamic difficulty adjustment) for balancing challenge with player skills; and, (3) adaptation of audio-visual effects.

\subsubsection{Adaptive automation of tasks}

Adaptive task automation techniques start automated assistance for game tasks when high player's workload is discovered or maintain an optimal level of vigilance during tasks execution [34] by operating negative feedback loop increasing task allocation when players become hypo-vigilant and vice versa. In addition, tasks' sequencing in gameplay can be monitored according to physiological responses measured by biometric sensors in order to provoke or suppress specific player emotions. In general, game tasks can be divided into three types [21]:

1) explicit tasks - such as objectives, goals and missions posed to the player as part of the gameplay;

2) implicit tasks - not explicitly stated by the game interface but expected to be fulfilled; such as "stay alive", "maximize your skills", or "collect as many items as possible";

3) player-driven tasks - created by the player thanks to his/her creativity within existing limitations of given game mechanics and leading to so called emergent gameplay [41] typical for Minecraft ${ }^{\mathrm{TM}}$ and other video games with no predefined narratives.

For the three types of tasks, game difficulty level can be adjusted automatically. 


\subsubsection{Adjustment of game difficulty level}

Traditional approaches of DDA, or so called dynamic game balancing, use player's performance as a base for dynamic control of task's difficulty by using a positive feedback loop [9]. Player performance allows straightforward realizations of DDA without any additional devices. In addition, interactive affective systems rely on affective loop adaptation [18] for reaching rich gameplay experiences. In a similar way, R a n i, S arkar and Li u [23] combined player's anxiety feedback for DDA by using negative feedback loop, with the traditional performance feedback for dynamic adaptation of game difficulty. In the same work, the feedback based on anxiety was found to be more effective than that one based on performance in regard of an immersive and challenging gameplay. Player's immersion was found to be strongly increased by using explicit, conscious player's control over game dynamics [33] unlike exploiting unconscious player's control. $\mathrm{Na} \mathrm{c} \mathrm{ke}$ et al. [32] used indirect, non-voluntary player's control based on physiological signals to manipulate successfully some game mechanics by changing values of game environmental variables. As Li u et al. [9] highlighted, methods for DDA applying only affective state information may appear not optimal. They propose experimenting with versatile DDA mechanisms considering "player's performance, his or her personality, and the context and complexity of the game among other issues to generate a rewarding gaming experience". Generally, approaches to DDA might be categorized in three types according to the method of adaptation [27]:

1. DDA by means of automatic level generation - uses methods for Procedural Content Generation (PCG), summarized by Yannakakis and Togelius [19] typically for platform games such as Nintendo's Super Mario Bros and its public domain clone Infinite Mario Bros. Textual and multimedia game content such as narrative, dialogues, quests, camera profiles, levels, textures, etc. - but excluding artificial intelligence for Non-Player Characters (NPC) - is created automatically by means of algorithmic procedures. PCG was initially introduced to the computer game offline, however, there are more and more recent approaches for online dynamic adaptation of content to changes of the player model.

2. DDA by means of modification of Artificial Intelligence (AI) - based on dynamic adaptation of difficulty of an intelligent NPC by picking out AI behaviour most relevant to the current state of the player's abilities and emotions. Modifications of NPC behaviour can include dynamic scripting (on-the-fly generation of different scripts for intelligent agents according to the player's behaviour), machine learning for NPC construction using genetic algorithms, or using adaptive agents [27].

3. DDA by means of adjusting level content, i.e., game items for player interactions - means dynamic adaptation of level of inventory interacted by the player for specific game context according to player's skill acquisition. Within Hamlet - a DDA system built using Valve's Half Life game engine - Hunicke and Chapman [40] define adjustment actions and policies for player's inventory. Reactive actions are used for adjusting "on stage" game items, while proactive actions adjust "off stage" (inactive) items. 


\subsubsection{Adaptation of audio-visual effects}

Finally, adaptation of audio-visual effects reflecting user's emotional state has initially been exploited within multimedia applications like affective music players, recommendation systems and online chat applications [29]. Dekker and $\mathrm{Ch}$ a m pi on [10] first tried enhancing the gameplay and display of a horror game mapping directly physiological player's responses to audio-visual game properties. Next, Gri g or e et al. [24] used stochastic algorithms for adapting ambient light in rooms within a video game by using psychophysiological features, namely player's heart rate and skin conductance. G a r $n$ e r [39] explored various psychophysiological approaches and sound design practices for creating greater emotional experiences in adaptive audio-centric gameplay, with a special focus on correlations between fear and game sound. Together with car steering and speed, road visibility was dynamically adjusted in a car racing game [34].

Besides the vertical classifications of the targets of dynamic adjustment of affective gaming consisting of three design levels as discussed over, another possible approach is to focus considerations primary on possible emotion elicitors in games. $\mathrm{Yannakakis}$ and $\mathrm{Paiva}$ [42] proposed a horizontal classification of target of adaptation in affective games including two main sources of possible emotion reactions: content adaptation and agents/NPC adaptation. They regard game content from a high level perspective considering here not only the game environment, plot, camera profiles, audio-visual settings and effects, but also game mechanics, dynamics and any types of content that can be adjusted to particular player's emotional state and, next, can affect player's gaming experience. The approaches of automatic and dynamic content generation as discussed over provide further opportunities towards affect-driven game content creation for synthesizing personalized experiences in the context of both entertainment and serious games [43]. On the other hand, the adaptation of game agents and NPCs with their complex cognitive, social and emotional behaviour is the second main source of emotion elicitations. Various types of NPC such as artificial tutors, companions, competitors, and crowds can be adapted according to game domain knowledge [44], player's emotional state [45] or player's experience and performance [37]. NPC behaviour includes reactive triggering emotional states as a response to a particular event as far as proactive expressing of emotions, which can be augmented by means of appropriate adaptive game content generation [42]. Both the adjustments of game content and agents/avatars/NPC go through adaptations of game mechanics, dynamics, and aesthetics.

\section{Player representation in affective game}

Together with the issues regarding possible targets of game adaptation in order to create stimuli for emotional elicitation at particular player, the affective loop poses the problem of detection and interpretation of emotions. Detecting changes in emotional state of a human player is a rather complex and challenging task, which requires establishing and exploitation of appropriate representation of the game player. 


\subsection{Modelling human emotions}

Emotions are usually easily understood by people, but their automatic recognition and measurement continues to be a complex and intricate problem. Human emotions are studied mainly from dimensional and discrete perspectives [7]. The most popular discrete categories of emotions used in systems for expression recognitions are the Big Six basic emotions: "happiness", "sadness", "fear", "anger", "disgust" and "surprise", as proposed by Ekma n, S or e n s o n and Frie se n [46]. The Big Six emotions are regarded as being innate, basic and determined in both psychological and biological sense. In some studies [47, 48], alongside this core set of emotions, another one or the "neutral" expression is proposed. In contrast to basic emotions, complex emotions such as pride, shame, and guilt have a much complex behavioural manifestations which substantially challenge their measuring [11]. Emotional expressions are strongly dependent on current personal moods - less specific and less intense than emotions but longer lasting and not consciously connected with a specific purpose [49]. As well, emotions are determined by personal affective disposition and affective personality traits - relatively permanent affective tendencies like the big-five five personality traits: neuroticism, extraversion, openness to experience, agreeableness, and conscientiousness [50].

In contrast to the discrete perspective, dimensional models organize emotional responses within a space with two or three fundamental dimensions. The Russell's circumplex model of affect [51] defines a two-dimensional core emotional space, where emotional valence ( $x$-axis) is the bipolar subjective evaluation of emotional feeling, and arousal ( $y$-axis) represents bipolar degree of mental activation or alertness. Besides valence and arousal, approach-avoidance motivations are used as behaviour functions presenting tendencies respectively to approach stimuli (reward acquisition) or to avoid stimuli (punishment avoidance) and, therefore, guiding behaviour either toward "maximizing acquisition of fitness-enhancing rewards" or towards "minimizing exposure to fitness-threatening punishers" [52] as shown in Fig. 2. Both the punishment avoidance and reward acquisition reflect behaviour activities of the affected person and are useful from decision-maker's perspective [53].

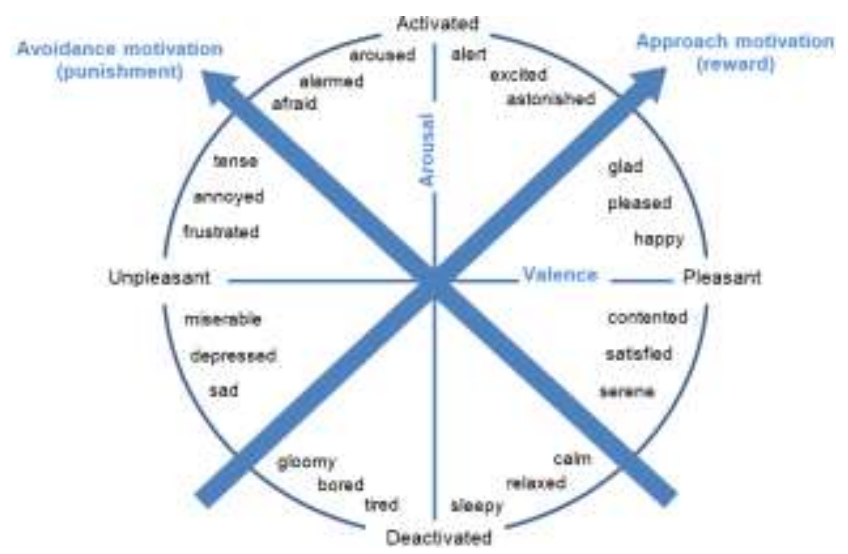

Fig. 2. The core emotional space with motivations to approach or avoid a stimulus $[51,53]$ 
Following the Russell's circumplex model, Mehrabian and R us se 11 [54] proposed a 3D environmental emotional scale of nearly independent bipolar dimensions abbreviated as PAD and including: (1) pleasure - indicates emotional valence, i.e., the extent of feeling happy or not; (2) arousal - measures the level of affective stimulation caused by the environment; and (3) dominance - refers to the degree of personal feeling of having control over a specific situation. As a whole, dimensional models effectively represent non-discrete emotional states and their variations over time [55] supposing discrete emotions do not have a specific biological basis, i.e., lacking brain region uniquely engaged with elicitation of given emotion.

\subsection{Flow, immersion and motivation}

Like other end-use products addressed to broader audience, modern video games aim at creating absorbing and engaging user experiences and, as well, positive and pleasurable feelings. While attempting to explain the origins of human happiness and creativity, Mihaly Csikszentmihalyi [56] developed the fundamental concept of flow, within a broad, long-lasting inter-racial study at many countries worldwide. During gameplay, the flow process of optimal experience - sometimes refereed as zone [38] or stretch zone [18] - has a balance between the inherent challenge of the game activity and the player's ability required for its execution (Fig. 3). When the challenge required by given game activity goes beyond player's skills, that activity becomes too overwhelming and starts provoking worry, anxiety, and arousal [57]. Low challenges failing in engaging the player fully evoke apathy and boredom, respectively for lower and middle player's skills; otherwise, such low challenges elicit feeling of relaxation and control. In general, people like being in a state of control due to feeling security and safety and, on the other hand, hate boredom [58]. The flow zone starts only if player's skills (ability to cope with the challenge) are higher-than-average and, at the same time, the challenge is above-average, i.e., above and to the right of the central point representing average flow and skills in Fig. 3. The flow zone for novice players is shifted to the control sector, while the flow zone for professional players is moved to the arousal sector. One possible shift to the flow zone is from apathy and boredom (if required challenge is relatively low compared to player's skills) through relaxation and control. While being in the flow zone, newly offered game challenges may surpass current player's skills, which will move the player to the arousal and anxiety sectors. Then, an adaptive adjustment of difficulty with strong decrease of challenge might bring the player again into the boredom sector.

Based on the flow concept, $\mathrm{S}$ w e e t s e $\mathrm{r}$ and W y e th [14] proposed a model for evaluating player enjoyment in computer games called GameFlow. Their model includes eight elements: concentration, challenge, skills, control, clear goals, feedback, immersion, and social interaction - all contributing essentially to player's enjoyment. The GameFlow model was revisited with detailed heuristics especially aimed for real-time strategy video games [22], where immersion is supported by 17 heuristics for narrative, graphics, sound, and gameplay. Unlike flow, immersion does not necessarily have a goal, but may be graduated. For defining levels of player's 
immersion in game, B row $\mathrm{n}$ and $\mathrm{Ca}$ ir n s [59] used the grounded theory within a qualitative study of analysis of players' feelings and identified three successive immersion levels: engagement, engrossment, and total immersion. While engagement is the initial level where player learns how to play, engrossment stays for player's familiarization with the game control. On the other hand, total immersion - sometimes used interchangeably with the concept of presence in complex virtual environments [60] - is distinguished with focusing on game modalities and allocation of mental resources to a given stimulus [15].

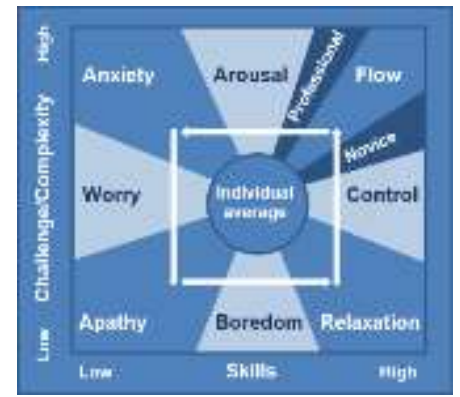

Fig. 3. Mental state as function of challenge and player's ability/skills [38, 57, 58]

Flow activities are autotelic and intrinsically motivated, therefore, the flow concept is strongly connected to motivation. Intrinsic motivation was defined by the self-determination theory [61] as "motivation based in the inherent satisfactions derived from action". The dynamic relation between the effort and the demand level is described as motivational intensity. With increasing the effort, it goes consequently through boredom, engagement, zone and overload (as shown by the white arrows' cycle in Fig. 3) and offers a model of motivational intensity for straightforward game adaptation [20]. Stretch zone [28] is defined for both high engagement and distress (overload of player's processing capacity) and is used by the adaptation controller for different adaptive responses for two states of low engagement - at low distress task demand which should be increased, and vice versa.

\section{Emotions in player-centric games}

\subsection{Measurement of emotions}

In last decades, various methods for measurement of emotions have been proposed depending on both the context and purpose of the assessment. Emotion measurement strategies are usually divided into three main groups [49]: self-reports, observational methods, and psychophysiological measurements.

\subsubsection{Self-reports}

Self-reports provide details about emotions by asking subjects specially constructed surveys or interviews to describe their emotions during passed time period or at the present moment. Bradley and Lang [62] developed the Self-Assessment Manikin (SAM) as a flexible alternative to verbal self-report measures. SAM visually 
depicts the three PAD dimensions (Pleasure, Arousal and Dominance) by representing each of them by five graphic characters along a nine-point scale. SAM was successfully used for assessment of player's valence and arousal within controlled experiments with the Pacman emotionally adaptive game [63]. Similarly to SAM, AffectButton [64] was proposed as another method for reliable and valid affective self-report by asking the user to select an emotional state interpretation of values of the three PAD dimensions shown as facial expression. While practical application of SAM requires considerable explanations of meaning of the dominance dimension (ibid), the AffectButton needs no user interpretation of all the three PAD dimensions

Another very popular instrument for psychometric self-report measurement of positive and negative affect (emotional valence) is the Positive and Negative Affect Schedule (PANAS) method proposed in [2]. This method consists of ten psychometric scales for lexical measuring emotional valence, namely excited, proud, inspired, and determined for positive affect, and scared, hostile, upset, and jittery for negative one. The PANAS method is proven in balanced research on emotions on both positive and negative emotional valences [65].

As a self-report measure of engagement in playing video games, the Game Experience Questionnaire (GEQ) was developed [66]. GEQ includes a core module dealing with actual experiences during gameplay, a social presence module covering gaming with others, and a post-game module concerning post-play player's experiences. GEQ was validated as a powerful instrument for assessing game engagement continuum in terms of adequate separation, rating scale functioning, and dimensionality $[48,60]$. For measuring self-reported mood, the UWIST Mood Adjective Checklist (UMACL) was proposed [67], which indexes energetic arousal, tense arousal, and hedonic tone.

Generally, self-reports represent cheap, convenient and well-accepted methods for measurement of emotions thanks to their self-referential nature and high face validity [49], however, they may be biased among certain groups of individuals who are not aware of (or competent in) revealing their emotional status [7] and might report on their beliefs about emotions rather than the emotions, which have occurred in reality. Self-reports are also limited by innate restrictions of human language and individual understanding of emotion labels [2].

\subsubsection{Observational methods}

Observational methods are based on observation, recording and interpretation of body movements or facial behaviour in order to infer specific emotions. In the last couple of years, many arguments and conclusions about game player experiences have been successfully inferred on the base of analyses of facial expressions $[48,68$, 69]. Ekman, S or en s on and Frie se n [46] developed recognition methods for facial expressions of six primary universal emotions as a basis for nonverbal behaviour and communication among people of various cultures. Next, a detailed Facial Action Coding System (FACS) was elaborated as a taxonomy system presenting movements of human facial muscles by coding characteristics of their changes and describing individual movements of the face muscles by action units 
[70]. Though FACS has been proven as a useful standard for categorization and measuring of emotional expressions [68], FACS-coded automatic recognition of facial expressions has different levels of recognition across cultures and even systematic miscategorisation of certain facial expressions in specific cultures because of some limitations like facial deformations and skin colour [71].

Feature-based approaches for facial observation classify different facial expressions by using facial feature trackers and analysing a small amount of features such as facial distances and angles limited between six and thirty [72]. Hu pont, Baldassarri and Cerezo [47] used a correlation-based feature selection technique in order to select most useful features from an initial set of distances and angles obtained from twenty characteristic facial points. Model-based approaches for facial expression recognition were conducted within unconstrained video environments with changes in illumination and face location showing high recognition accuracy and robustness [69]. Ta n, B akkes and Pis an [48] conducted experiments with a FPS game (Portal 2) and with a social drawing trivia game, in order to infer joy, surprise, and anger, plus neutral expressions. Recently, facial expression recognition SDK's are used for modelling and unobtrusively inferring player affective state and player experience, based on analysis of facial expressions [73].

As a whole, facial and body movements' observation provide rich data and, though being expensive and time consuming [49], are very useful for examining the expression of emotions. On other hand, their validity in some cases might be problematic in terms of subjective issues such as gender and personal expressiveness [7]. Inferring human emotions based on facial expression recognition of the subjects may be problematic when emotions are intentionally expressed, suppressed or even hidden during the observation, which varies between cultures, races and social environments [74]. Therefore observational methods should supplement self-reports but not replace them totally.

\subsubsection{Psychophysiological measurements}

Physiological signal analysis is a method providing a more natural way for human emotions recognition as far as physiological activities and changes are direct reflections of processes in central and autonomic nervous systems. Physiological data are translated to psychological states by extraction of some specific features from measured physiological signals [75]. Next, the most popular features are picked out in order to be used for classification or estimation of discrete emotion classes by means of various machine learning methods or statistical approaches [29]. Adaptive affective games mainly use several groups of physiological signals (monitoring modalities). These measured physiological responses are either produced by ANS reflecting cardiovascular, electro-dermal, and muscle activities are indicators of CNS functioning representing electrical activity of human brain.

The most popular ANS measures used in adaptive player-centric games are the ones of cardiovascular, electro-dermal, and muscle activities. Traditionally, cardiovascular activity is measured by means of electrocardiography (ECG). ECG is used to extract the subject's Heart Rate (HR) and Heart Rate Variability (HRV). HRV 
represents adaptation changes in the time intervals between adjacent heartbeats in response with environmental and/or internal stimuli [76]. The adaptation mechanisms of HRV are in response to activities of the sympathetic and parasympathetic nervous systems, where [77] provides a detailed review of origins, methods, and caveats about HRV. Another, less popular than ECG, way to calculate HRV is based on measuring Blood Volume Pulse (BVP) signal [78]. BVP is a relative measure and represents percent of blood vessel pressure [16] using a less obtrusive sensor than ECG. Time needed for BVP to return to its normal level indicates the extent of feeling the emotion.

Electro-Dermal Activity (EDA), often referred to as Galvanic Skin Response (GSR), is a measure of skin conductance response. The epidermis has a pronounced activity that is directly related to the activity of the sweat glands, which are regulated by the sympathetic nervous system [79]. EDA represents the electrical conductivity of the skin, which is directly dependent on the activity of the sweat glands, which in turn is related to the function of the sympathetic nerve. EDA contains two main components: tonic skin conductance meaning response baseline during absence of any specific discrete environmental changes, and phasic skin conductance applying to possible events that happen [9]. Thanks to its simplicity and low cost measuring techniques, EDA continues enjoying wide popularity - alone or combined with other techniques [80] - for finding correlations with the player experience and affective changes in player state. Applying only EDA measurements for inferring emotional arousal and stress has a proven strong content validity [28].

Electromyography (EMG) is a non-invasive electro-diagnostic method for registration of electrical activity produced by muscles of the skeleton and/or the face [81]. Electromyograms represent graphically electrical potentials recorded by surface electrodes and produced by muscles as reaction of electrical or neurologic stimuli. Together with EDA and HRV, EMG features were employed for real time adjustment of game speed in an emotionally adaptive version of Pacman [63] resulting in larger movements in the zygomaticus major muscle with more positive valence reports for higher speeds. In [78] this algorithm was compared to the EDA-based algorithm for stress detection proposed by $\mathrm{Heale} \mathrm{y} \mathrm{and} \mathrm{Picard}$ [82] in the research context of biofeedback-based relaxation training. Both the algorithms are proven to have similar effectiveness, which makes the authors suppose they will produce similar results in biofeedback games.

Besides employing physiological responses reflecting cardiovascular, electrodermal, and muscle activities, affective applications may use some other ANS measures for emotional-based adaptation. RESPiration (RESP) rate and skin TEMPerature (TEMP) may be affected by arousal and emotional states like joy, anger and anxiety $[9,83]$. Rarely, an adaptive affective game may use KEYBoard pressure (KEYB) [63] as a measure indicating changes in individual player effort or emotion at playing the game.

In contrast to the ANS methods, electroencephalography (EEG) and other neuroimaging methods measure electrical activity caused spontaneously by functioning of the central nervous system. They try to extract information relevant to human thoughts and emotions in a non-invasive way by placing electrodes on the 
scalp and amplifying the signal. Cognitive psychology and physiology measures event-related potentials provoked as reaction to external physical stimuli [6]. EEG is a method for observing rhythmic macroscopic neural oscillations produced by synchronized activity of brain neurons. These oscillations are observed in specific frequency ranges named as alpha $(8-13 \mathrm{~Hz})$, delta $(1-4 \mathrm{~Hz})$, theta $(4-8 \mathrm{~Hz})$, beta $(13-30 \mathrm{~Hz})$ and gamma $(30-70 \mathrm{~Hz})$ frequency bands and are highly used for studying neuropsychiatric diseases [84]. EEG is known by its high temporal resolution - on the order of milliseconds - which requires sampling higher rates, however, it offers low spatial resolution of the brain [85]. On other side, neuroimaging methods [7] such as magnetoencephalography (MEG), functional Magnetic Resonance Imaging (fMRI) and Positron Emission Tomography (PET) are proven as being more precise in assessment of brain activity location and hence to identify brain structures responsible to specific emotions. They provide better temporal resolution but are more expensive and used primarily for clinical research. A much cheaper, safer, and highly portable alternative to fMRI is the multi-wavelength optical spectroscopy technique called functional Near Infrared Spectroscopy (fNIR), which measures hemodynamic brain responses resulting from intentional sensory, motor, or cognitive activities [86]. fNIR serves for assessment of temporal progression of brain activity and offers good spatial resolution.

\subsection{Processing and interpretation of physiological signals}

The work of Picard, Vyzas and Healey [75] gave rise to hundreds of other studies in emotional and cognitive inferences based on physiological responses were conducted by reflecting these four criteria to a greater or lesser extent. All of them include measuring physiological signals, extraction of specific features from the measured responses, selection of the most appropriate features, using them for psychophysiological inference and, finally, adapting the affective computing system according to the inferred emotions of individual user in a smart way [28]. N o vak, Mihelj and Munih [29] provided a more detailed presentation of the general process of measuring, interpreting and using ANS responses in physiologically adaptive computing systems, in particular adaptive affective games. As presented in Fig. 4, measured raw physiological signals are recorded at the first stage of the process. At the second stage, they are used for extracting a number of features relevant for the type of psychophysiological measure. Next, extracted psychophysiological feature may be optionally normalized in term of reducing both intra- and inter-subject variability and possible differences in numerical ranges, by means of subtraction of (or division to) the baseline value or by subtracting the mean value and dividing the result by the standard deviation of all feature vectors. Dimension reduction is the second optional stage in the process, where the most relevant features are identified and selected in order to decrease both the cost and complexity of next data processing. At the third stage of the process, the feature vector (with possibly reduced size) is used at the data fusion stage, which is defined as "classification or estimation of psychological states from multiple psychophysiological relevant features obtained from different physiological signals". 
Finally, the inferred psychological states are used for appropriate system adaptation at the fourth process stage.

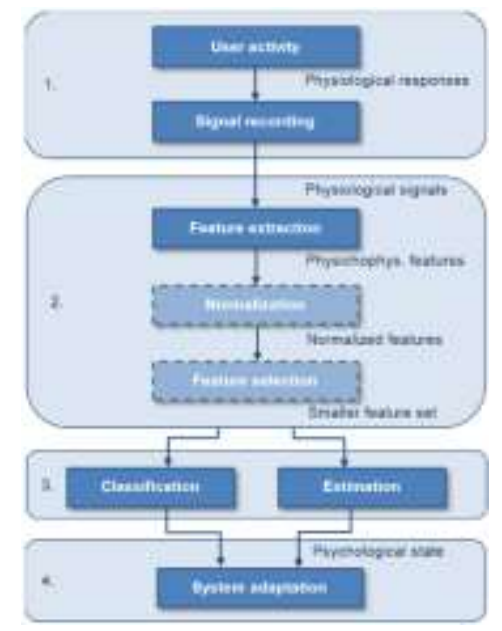

Fig. 4. Stages in measuring and processing psychophysiological signals in affective systems [29]

As shown in Fig. 4, classification and estimation are two alternative ways for making data fusion, i.e., for assigning a psychological label to the feature vector. Classification is a process of determining a categorical label for the feature vector, which consists of one or more psychological classes like "boredom", "arousal" or "worry". Different classification methods are compared in [29] such as k-Nearest Neighbour (kNN), Bayesian Networks (BNT), Regression Trees (RT) and Decision Trees (DT) [9], Naïve Bayes Classifier (NBC) [86], Linear Discriminant Analysis (LDA) [87], and Support Vector Machines (SVM) [83], as well. As the authors note, direct comparison of their accuracy rates is dependent on types of extracted features, normalization method and ways for reducing features vector dimension. Usually, researchers implement several classifiers and compare their accuracy by means of cross-validation on the training data set. With regard to transparency, classification trees and LDA are mostly preferred, whereupon LDA has easiest implementation. Experiments with relatively small sample mostly use LDA, while for classifying larger samples SVM and ANN are preferred. On the other hand, estimation methods like linear regression [20, 88], fuzzy logic [89] and artificial neural networks [16] assign a continuous value within given numerical interval for the psychological state. Estimation appears preferable to classification, when the goal of adaptation is to adjust a continuous value like in the case of DDA [27, 89]. However, when game adaptation is based on several discrete levels of a psychological variable like arousal or valence, classification methods are employed [9].

\section{Adaptation in modern affective games}

After providing a review of the methods and techniques of applying affective feedback in video games for realisation of specific targets of adaptation using emotion recognition based on models of player emotions, flow, immersion and 
motivation, the study aims at investigation how modern affective games apply these adaptation methods and techniques in practice and how they are experimentally validated.

\subsection{Research questions}

After the pioneer work of by B ersak et al. [4] with their Relax-to-Win affective game, there were created and experimented in controlled conditions many other affective computing applications recognizing changes in emotional state by measuring player's physiological signals and reacting to them by adapting some application features. Other reviews in the area of affective computing are mainly focused on the fundamentals of physiological computing [28], automatic classification of emotions using physiological signals [80], or data fusion methods [29], but not on specific problems of adaptation in affective video games. With respect to the last, there have to be discussed not only details about emotional recognition such as measuring methods and classification accuracy but, as well, issues like targets of adaptation and type of adaptation strategies. Therefore, three main Research Questions (RQ) were identified, as follows:

- RQ1. What types of emotionally adaptive video games have been created and what game features have been adapted using affect-based adaptation techniques?

- RQ2. Which combination of sensors, hardware devices and methods are applied to obtain psycho-physiological measures and associated features in order to recognise specific emotions for being used for game adaptation?

- RQ3. What are the objectives of conducted experimental studies and what outcomes of applying emotional adaptation in video games were found and practically validated regarding player experience?

\subsection{Method}

\subsubsection{Literature research}

The literature research aimed at finding a great quantity of journal articles, conference papers, theses and technical reports concerning adaptation models, mechanisms and practices used in affective video games. For this purpose, online databases relevant to information technology and social sciences were searched for relevant literature, such as Google Scholar, Science Direct, ACM Digital Library, IEEE Xplore Digital Library, Emerald, BioMed Central, PsychInfo, ERIC (Education Resources Information Center), EBSCO, ResearchGate, ProQuest Dissertations and Theses (Index to Theses), OERCommons for open educational resources [90], and Academia. On the other hand, many studies were collected manually by following references of literature.

There search terms addressing adaptive digital games with regards to the variety of existing computer games types and genres, were used, including terms like "video game", "entertainment game", "games for fun", "serious game", "applied game", or "educational game". Game search term were used in conjunction with terms addressing adaptation and affect, such as "affective gameplay", "player-centric models", "emotionally adaptive game", "psychophysiological measure", "feature 
extraction", "emotion recognition", and "emotion inference". Another conjunction was used regarding practical experiments conducted for validation of outcomes of affective adaptation - by applying search terms like "game based learning", "satisfaction", "immersion", "motivation", and "learnability".

\subsubsection{Papers' selection for inclusion in the review}

The research process was carried out in two stages: since September 2014 until January 2015 and, next, since August 2015 until the end of the year. There were systematically reviewed more than 300 papers relevant to the search terms. All of them presented research works in the field of behavioural signal processing used for emotion recognition; however, relatively few of them were developed in an ecologically valid context such as computer gameplay. On other hand, many of found studies of emotions in game play aimed only at discovering some elicited emotional responses to game events such as of arousal, valence, boredom, frustration or dominance $[63,89]$, or at exploring dependencies between physiological signals and gameplay preferences and experiences $[16,60]$. All of this research demonstrates significant correlations between objectively measured affect signals and player's experiences subjectively reported by means of self-report methods like SAM and GEQ, however, they do not apply the inferred emotions for adaptation of any game features [42].

In order to answer the three research questions, the review should embrace research trends especially in modern adaptive video games, where affective correlates to player's physiology are actively used for adaptation of game mechanics, dynamics and aesthetics. With this purpose, several criteria were used for the papers' selection for inclusion in the review: (1) the paper should present a video game adapted by means of affect-based adaptation techniques; (2) the study should reflect adaptation methods, psychophysiological measurement techniques and eventual features and devices applied to recognise specific emotions; (3) objectives of conducted experimental study, validation results and outcomes of affect-based game adaptation should be outlined; (4) papers reflecting different aspects of same study were treated together; (5) the paper should be written in English and published during last 10 years.

No other limitations concerning particular publication type or research methods were applied. From over 300 initially collected articles, only 14 studies were selected for comparison in the review.

\subsection{Findings and discussion}

Selected studies represent 14 video games with affect-based adaptation developed in last ten years and reveal the specific problems of adaptation in affective video games. Review findings are organised in three groups according to the research questions with categorisation dimensions as follows:

1. Affective video game properties - include literature reference(s), name of the affective digital game, primary game purpose (for entertainment or applied game), game genre (incl. dimension of the space), delivery platform, gameplay mode (singleor multi-player), and adapted game features. 
2. Technological and methodological issues of realisation of affective games comprises affective feedback type - negative, positive, or Combined (C), measured psychophysiological signals, extracted features, biofeedback device, sampling rate $(\mathrm{Hz})$, duration of time window (s), calibration period ( $\mathrm{min}$ ), applied signal filtering, recognized emotions, method for emotion classification or estimation, and achieved accuracy.

3. Experimental validation, outcomes and impact of the affect-based adaptation - covers the objectives of the study (presented here in order to be juxtaposed to the results); chosen experimental method - such as Randomized Control Trial (RCT), Quasi-Experimental Design (QED), or case study; number of subjects (participants) in the experiment; age interval and age mean; gender balance; previous game experience of subjects (if any); number of game sessions and session time (min.); self-report means such as questionnaires and interviews and, finally, results and conclusions about adaptation benefits and shortcomings.

Table 1 represents a comparison between the affective video game properties. Empty cells anywhere in the table mean no information is available on the respective issue. The majority of the studied affective games have as a primary purpose entertainment. Only two of these 14 games are created with applied purpose - in the area of team cognition, communication and coordination [91, 92] and clinical studies of concentration level [93]. The game genre is quite diverse, whereupon games either are variants of simple old arcade (archery, Pong and Pac-man) and puzzle (Tetris) games, or are modifications of popular FPS, platform or car racing games. All the games are desktop applications (in three of the cases, with additional game controllers) excluding game No 5, which is created using augmented-reality over the Playware playground platform [16]. Single-player appears to be the preferred mode for experimental games, with exclusion for games No 6 and 14 (two-player) and No 1 and 7 (multiple-player).

For the arcade and puzzle games, one or few game features are adapted concerning only DDA. On other hand, more complex video games provide more opportunities for affect-based adaptation - not only concerning DDA but adjusting audio-visual properties [92] like environmental density and gravity [10], territorial control [93], tunnel vision effects [91], and visibility [34]. As well, some of them adapt skills of NPC [87] or other properties of opponents like enemy spawn, health and weapon control, and boss appearances [17].

Table 2 reveals practical technological and methodological issues of realisation of the same affective games as these listed in Table 1. Adaptation mechanisms include mainly positive affective feedback - for increasing performance, fun and randomness of the game [34], or negative feedback - for creation of behavioural stability, during the play [94]. Some of the games use more complex adaptive algorithms switching from positive to negative biofeedback and vice versa in cases of specific emotional states and thresholds of the player, in order to keep the player in the flow zone. Affective adaptations are accomplished mainly by using ANS signals obtained by ECG, PPG, GSR, EMG or measuring of respiration rhythms, temperature or keyboard pressure. Only two of the analysed affective games make use of EEG, namely alpha and theta rhythms [20,84]. Obviously, ANS measurements 
appear to be more popular in affective gaming than using CNS signals, as far as ANS measures represent mainly emotional dimensions rather than discrete emotions [7]. CNS signals are used for extracting relatively small number of features (two or three), while the features of ANS signals $(\mathrm{M}=4.60, \mathrm{SD}=5.08)$ are found to vary from 1 to 17 [9] per signal. In cases of more extracted features, feature selection is accomplished aiming at finding an optimal set of signal features. Among the various methods for future selection, the Sequential Feature Selection (SFS) appears to be mostly used with respect to maximization of the classification performance [29].

Table 1. Properties of affective video games

\begin{tabular}{|c|c|c|c|c|c|c|c|}
\hline $\mathrm{N}$ & $\begin{array}{l}\text { Refe- } \\
\text { rences }\end{array}$ & Game name & $\begin{array}{l}\text { Game } \\
\text { purpose }\end{array}$ & $\begin{array}{l}\text { Game } \\
\text { genre }\end{array}$ & $\begin{array}{l}\text { Delivery } \\
\text { platform }\end{array}$ & Mode & Adapted game features \\
\hline 1 & [92] & $\begin{array}{l}\text { PhysiRogue (on } \\
\text { Rogue Signals } \\
\text { game) }\end{array}$ & applied & $2 \mathrm{D}$ action & $\begin{array}{l}\text { desktop, GPS- } \\
\text { location-aware }\end{array}$ & $\begin{array}{l}\text { multi- } \\
\text { ple- } \\
\text { player } \\
\end{array}$ & $\begin{array}{l}\text { Seekers' desirability of } \\
\text { predators, player visual } \\
\text { representation }\end{array}$ \\
\hline 2 & [10] & Half-Life 2 & $\begin{array}{l}\text { entertain- } \\
\text { ment }\end{array}$ & 3D FPS & desktop & $\begin{array}{l}\text { single- } \\
\text { player }\end{array}$ & $\begin{array}{l}\text { Avatar speed, sound volume, } \\
\text { environmental density, gravity, } \\
\text { and transparency; weapon } \\
\text { damage; red and b/w filters; } \\
\text { NPC creation }\end{array}$ \\
\hline 3 & $\begin{array}{l}{[63,} \\
96]\end{array}$ & $\begin{array}{l}\text { EMO-Pacman } \\
\text { (on Pac-Man } \\
\text { game) }\end{array}$ & $\begin{array}{l}\text { entertain- } \\
\text { ment }\end{array}$ & $2 \mathrm{D}$ arcade & desktop & $\begin{array}{l}\text { single- } \\
\text { player }\end{array}$ & Objects' speed \\
\hline 4 & [83] & Tetris & $\begin{array}{l}\text { entertain- } \\
\text { ment }\end{array}$ & 2D puzzle & desktop & $\begin{array}{l}\text { single- } \\
\text { player }\end{array}$ & Speed of falling Tetris blocks \\
\hline 5 & $\begin{array}{l}{[16,} \\
97]\end{array}$ & $\begin{array}{l}\text { Bug-Smasher } \\
\text { (a Playware } \\
\text { ambient game) }\end{array}$ & $\begin{array}{l}\text { entertain- } \\
\text { ment }\end{array}$ & $\begin{array}{l}\text { physical } \\
\text { platform }\end{array}$ & $\begin{array}{l}\text { Playware } \\
\text { playground } \\
\text { platform }\end{array}$ & $\begin{array}{l}\text { single- } \\
\text { player }\end{array}$ & $\begin{array}{l}\text { Bugs' speed and the entropy of } \\
\text { bug-visited tiles }\end{array}$ \\
\hline 6 & [9] & Pong & $\begin{array}{l}\text { entertain- } \\
\text { ment }\end{array}$ & $2 \mathrm{D}$ arcade & desktop & $\begin{array}{l}\text { two- } \\
\text { players }\end{array}$ & $\begin{array}{l}\text { Speed and size of both ball and } \\
\text { paddle; sluggish or } \\
\text { overresponsive keyboard }\end{array}$ \\
\hline 7 & $\begin{array}{l}{[86,} \\
93]\end{array}$ & $\begin{array}{l}\text { MindTactics } \\
\text { (Unity3D } \\
\text { game) }\end{array}$ & applied & $\begin{array}{l}3 \mathrm{D} \\
\text { strategy }\end{array}$ & desktop & $\begin{array}{l}\text { single/ } \\
\text { multi- } \\
\text { player }\end{array}$ & $\begin{array}{l}\text { Territorial control and } \\
\text { distractors }\end{array}$ \\
\hline 8 & [87] & $\begin{array}{l}\text { A 3D games on } \\
\text { TORCS }^{1}\end{array}$ & $\begin{array}{l}\text { entertain- } \\
\text { ment }\end{array}$ & racing & desktop & $\begin{array}{l}\text { single- } \\
\text { player }\end{array}$ & Opponent skill \\
\hline 9 & [32] & $\begin{array}{l}\text { 2D Xbox } 360 \\
\text { FPS game }\end{array}$ & $\begin{array}{l}\text { entertain- } \\
\text { ment }\end{array}$ & $\begin{array}{l}\text { 2D side- } \\
\text { scrolling } \\
\text { shooter }\end{array}$ & $\begin{array}{l}\text { desktop with } \\
\text { Microsoft Xbox } \\
360 \text { controller }\end{array}$ & $\begin{array}{l}\text { single- } \\
\text { player }\end{array}$ & $\begin{array}{l}\text { Enemy target size, flame } \\
\text { length, speed and jump height, } \\
\text { weather conditions and boss } \\
\text { speed }\end{array}$ \\
\hline 10 & [20] & Tetris & $\begin{array}{l}\text { entertain- } \\
\text { ment }\end{array}$ & 2D puzzle & desktop & $\begin{array}{l}\text { single- } \\
\text { player }\end{array}$ & Speed of falling Tetris blocks \\
\hline 11 & [84] & Archery game & $\begin{array}{l}\text { entertain- } \\
\text { ment }\end{array}$ & shooting & desktop & $\begin{array}{l}\text { single- } \\
\text { player }\end{array}$ & Archery focus level \\
\hline 12 & $\begin{array}{l}{[88,} \\
91]\end{array}$ & VANISH & $\begin{array}{l}\text { entertain- } \\
\text { ment }\end{array}$ & 3D FPS & desktop & $\begin{array}{l}\text { single- } \\
\text { player }\end{array}$ & $\begin{array}{l}\text { Event probabilities, PCG and } \\
\text { tunnel vision effects; } \\
\text { character's movement speed, } \\
\text { stamina, and sanity level }\end{array}$ \\
\hline 13 & [34] & $\begin{array}{l}\text { Car racing } \\
\text { game }\end{array}$ & $\begin{array}{l}\text { entertain- } \\
\text { ment }\end{array}$ & $3 \mathrm{D}$ racing & $\begin{array}{l}\text { desktop, } \\
\text { Logitech G27 } \\
\text { racing wheel }\end{array}$ & $\begin{array}{l}\text { single- } \\
\text { player }\end{array}$ & Visibility, steering, and speed \\
\hline 14 & [94] & $\begin{array}{l}\text { BioPong (based } \\
\text { on the Pong } \\
\text { game) }\end{array}$ & $\begin{array}{l}\text { entertain- } \\
\text { ment }\end{array}$ & $2 \mathrm{D}$ arcade & desktop & $\begin{array}{l}\text { two- } \\
\text { players }\end{array}$ & Ball speed, paddle size \\
\hline
\end{tabular}

\footnotetext{
${ }^{1}$ The Open Racing Car Simulator (TORCS) 
Table 2. Technological and methodological issues of realisation of affective games

\begin{tabular}{|c|c|c|c|c|c|c|c|c|c|c|c|}
\hline No & $\mathrm{FT}^{2}$ & Measured signals & $\mathrm{F}^{3}$ & $\begin{array}{l}\text { Biofeed-back } \\
\text { device }\end{array}$ & $\begin{array}{l}\text { Rate } \\
(\mathrm{Hz})\end{array}$ & $\begin{array}{l}\text { Time } \\
\text { win- } \\
\text { dow } \\
\text { (s) } \\
\end{array}$ & $\begin{array}{l}\text { Cali- } \\
\text { bra- } \\
\text { tion } \\
(\mathrm{min}) \\
\end{array}$ & Signal filtering & $\begin{array}{l}\text { Recognized } \\
\text { emotions }\end{array}$ & $\begin{array}{l}\text { Classifi- } \\
\text { cation / } \\
\text { estima-tion }\end{array}$ & $\begin{array}{l}\text { Accu- } \\
\text { racy } \\
(\%)\end{array}$ \\
\hline 1 & + & $\begin{array}{l}\text { Phasic EMG } \\
\text { Phasic EDA } \\
\text { Tonic EMG } \\
\text { Tonic EDA }\end{array}$ & $\begin{array}{l}1 \\
1 \\
1 \\
1\end{array}$ & $\begin{array}{l}\text { ProComp2 } \\
\text { (Thought } \\
\text { Techn.) }\end{array}$ & $\begin{array}{l}10 \\
0,33 \\
10 \\
0,33\end{array}$ & $\begin{array}{l}1 \\
30 \\
6 \\
300\end{array}$ & & Kalman filter & Stress level & $\begin{array}{l}\text { Direct } \\
\text { mapping }\end{array}$ & \\
\hline 2 & + & $\begin{array}{l}\text { HRV (ECG) } \\
\text { HR } \\
\text { EDA }\end{array}$ & $\begin{array}{l}2 \\
2 \\
2 \\
\end{array}$ & $\begin{array}{l}\text { Lightstone } \\
\text { (Wild Divine) }\end{array}$ & & 2 & 5 & $\begin{array}{l}\text { Average } \\
\text { downsampling at } \\
2 \mathrm{~s}\end{array}$ & Horror & $\begin{array}{l}\text { Direct } \\
\text { mapping }\end{array}$ & \\
\hline 3 & - & $\begin{array}{l}\text { BVP } \\
\text { EDA } \\
\text { EMG } \\
\text { RESP } \\
\text { KEYB } \\
\end{array}$ & 4 & $\begin{array}{l}\text { NeXus and } \\
\text { Biotrace+ } \\
\text { (Mind Media) }\end{array}$ & $\begin{array}{l}128 \\
32 \\
1024 \\
32 \\
100 \\
\end{array}$ & 180 & & $\begin{array}{l}\text { High-pass } \\
\text { Chebyshev } 20 \mathrm{~Hz} \\
\text { filter; smoothing } \\
\text { filter }\end{array}$ & $\begin{array}{l}\text { Boredom, } \\
\text { frustration and } \\
\text { enjoyment }\end{array}$ & $\begin{array}{l}\text { Direct } \\
\text { mapping }\end{array}$ & \\
\hline 4 & $\mathrm{C}$ & $\begin{array}{l}\text { EDA } \\
\text { BVP } \\
\text { HR } \\
\text { RESP } \\
\text { TEMP } \\
\end{array}$ & $\begin{array}{l}4 \\
2 \\
3 \\
3 \\
2 \\
\end{array}$ & $\begin{array}{l}\text { Biosemi } \\
\text { Active } 2\end{array}$ & 1024 & 20 & 1.5 & $\begin{array}{l}\text { Moving average } \\
\text { filters }\end{array}$ & $\begin{array}{l}\text { Boredom, } \\
\text { anxiety, and } \\
\text { engage-ment }\end{array}$ & SVM & 53.33 \\
\hline 5 & + & $\begin{array}{l}\text { HR } \\
\text { BVP } \\
\text { EDA }\end{array}$ & $\begin{array}{c}13 \\
7 \\
13\end{array}$ & $\begin{array}{l}\text { ProComp Inf. } \\
\text { (Thought } \\
\text { Techn.) }\end{array}$ & 256 & 45 & 0 & $\begin{array}{l}\text { Discrete Fourier } \\
\text { Transform } \\
\text { (DFT) filter }\end{array}$ & $\begin{array}{l}\text { Entertainment } \\
\text { value }\end{array}$ & ANN & 79.76 \\
\hline 6 & $\mathrm{C}$ & $\begin{array}{l}\text { ECG } \\
\text { PPG } \\
\text { EDA } \\
\text { EMG } \\
\text { TEMP } \\
\end{array}$ & $\begin{array}{c}17 \\
3 \\
5 \\
16 \\
3 \\
\end{array}$ & $\begin{array}{l}\text { Biopac } \\
\text { (BIOPAC } \\
\text { Systems) }\end{array}$ & 1000 & $\begin{array}{l}0.025 \\
0.1\end{array}$ & & $\begin{array}{l}\text { Low-pass filters, } \\
\text { DFT, wavelets }\end{array}$ & Anxiety level & $\begin{array}{l}\text { RT } \\
\text { kNN } \\
\text { BNT } \\
\text { SVM }\end{array}$ & $\begin{array}{l}88.5 \\
80.4 \\
80.6 \\
88.9\end{array}$ \\
\hline 7 & + & fNIR & 4 & $\begin{array}{l}\text { Bespoke fNIR } \\
\text { device }\end{array}$ & 2048 & 16.5 & 0.33 & $\begin{array}{l}\text { Low-pass cut-off } \\
\text { frequency filter } \\
(0.14 \mathrm{~Hz})\end{array}$ & Attention level & $\begin{array}{l}\text { kNN } \\
\text { NBC }\end{array}$ & $\begin{array}{l}73.77 \\
57.37\end{array}$ \\
\hline 8 & + & $\begin{array}{l}\text { BVP } \\
\text { ECG } \\
\text { EDA } \\
\text { RESP } \\
\text { TEMP } \\
\end{array}$ & $\begin{array}{l}11 \\
11 \\
11 \\
11 \\
11 \\
\end{array}$ & $\begin{array}{l}\text { ProComp } \\
\text { Infinity } \\
\text { (Thought } \\
\text { Techn.) }\end{array}$ & $\begin{array}{l}2048 \\
2048 \\
256 \\
256 \\
256 \\
\end{array}$ & 60 & 1 & Horror & $\begin{array}{l}\text { Preference } \\
\text { level }\end{array}$ & LDA & 74 \\
\hline 9 & + & $\begin{array}{l}\text { BVP } \\
\text { EDA } \\
\text { ECG } \\
\text { EMG } \\
\text { RESP } \\
\text { TEMP } \\
\end{array}$ & $\begin{array}{l}1 \\
1 \\
1 \\
1 \\
1 \\
1 \\
\end{array}$ & $\begin{array}{l}\text { Flexcomp } \\
\text { Infinity } \\
\text { (Thought } \\
\text { Techn.), } \\
\text { TTLAPI }\end{array}$ & 2048 & & 10 & $\begin{array}{l}\text { Chebyshev type } \\
\text { II filters, } \\
\text { downsampling } \\
\text { by } 64\end{array}$ & $\begin{array}{l}\text { Preference } \\
\text { level }\end{array}$ & $\begin{array}{l}\text { Direct } \\
\text { mapping }\end{array}$ & \\
\hline 10 & $\mathrm{C}$ & $\begin{array}{l}\text { Alpha \& theta } \\
\text { (EEG) }\end{array}$ & 2 & & & 2 & 2 & & $\begin{array}{l}\text { Boredom, } \\
\text { engage-ment, } \\
\text { flow, overload }\end{array}$ & $\begin{array}{l}\text { Linear } \\
\text { estima-tion }\end{array}$ & \\
\hline 11 & $\mathrm{C}$ & Alpha (EEG) & 3 & $\begin{array}{l}\text { Bespoke } \\
\text { device }\end{array}$ & 256 & 2 & 3 & $\begin{array}{l}\text { FFT band-pass } \\
\text { filter }(0.5 \sim 50 \mathrm{~Hz})\end{array}$ & Focus level & $\begin{array}{l}\text { Direct } \\
\text { mapping }\end{array}$ & \\
\hline 12 & $\mathrm{C}$ & $\begin{array}{l}\text { BVP } \\
\text { EDA } \\
\text { EMG }\end{array}$ & $\begin{array}{l}2 \\
2 \\
1\end{array}$ & $\begin{array}{l}\text { Nexus-10 } \\
\text { (Mind Media) } \\
\text { and } \\
\text { BioTrace+ } \\
\end{array}$ & $\begin{array}{l}32 \\
32 \\
1024\end{array}$ & $\begin{array}{l}2 \\
5 \\
0.125\end{array}$ & 5 & $\begin{array}{l}\text { Smoothing filter } \\
\text { (moving } \\
\text { average) }\end{array}$ & $\begin{array}{l}\text { Arousal and } \\
\text { valence levels }\end{array}$ & $\begin{array}{l}\text { Linear / } \\
\text { nonlinear } \\
\text { regre-sions }\end{array}$ & 85 \\
\hline 13 & + & EDA & 1 & $\begin{array}{l}\text { FlexComp } \\
\text { (Thought } \\
\text { Techn.) } \\
\end{array}$ & 1 & 30 & 8 & & Arousal & $\begin{array}{l}\text { Direct } \\
\text { mapping }\end{array}$ & \\
\hline 14 & $\mathrm{C}$ & $\begin{array}{l}\text { EDA } \\
\text { HR } \\
\end{array}$ & $\begin{array}{l}1 \\
1 \\
\end{array}$ & Arduino & & & 0 & & Arousal & $\begin{array}{l}\text { Direct } \\
\text { mapping }\end{array}$ & \\
\hline
\end{tabular}

With regard to biofeedback devices, three types of hardware are used: (1) simple and cheap (up to several hundreds of USD) commercial devices like U3-HV by LabJack Corp. and Lightstone by Wild Divine; (2) powerful, multichannel and expensive (up to several thousands of USD) commercial systems such as ProComp Infinity of Thought Technologies; (3) custom home-made devices, e.g., based on Arduino platform [94]. The measurement sampling rate varies highly - from $0.33 \mathrm{~Hz}$ up to $2048 \mathrm{~Hz}$, although rates greater than $200-400 \mathrm{~Hz}$ are recommended for psychophysiological measurements [95]. Signals measured with a sample rate higher

${ }^{2}$ Feedback Type (FT)

${ }^{3}$ Features $(\mathrm{F})$ 
than $1 \mathrm{kHz}$ are next down-sampled for feature extraction. The time window for analysed signal features differs from $0.025 \mathrm{~s}$ to $180 \mathrm{~s}(\mathrm{M}=26.05, \mathrm{SD}=48.18)$ and depends on measured signal, extracted feature and adaptation purpose. Adoption of a rather short time window hides risks of strong influence of sudden fluctuations in measured signal value, which may compromise the experiment. On other hand, choosing a rather long time window reduces the sensitivity of the adaptive loop [20]. Eventually, the duration of time window may depend on the time of field trial sessions, which vary from several minutes for arcade and racing games up to hours for video games like MindTactics [86]. Calibration periods are applied only in nine of the experiments with calibration time $(\mathrm{M}=3.98, \mathrm{SD}=3.31)$ from 0.33 up to $10 \mathrm{~min}$.

In eleven of the studies, raw signals are filtered for removing noise and/or for separating high from low frequency bands. Extracted signal features either are used for emotion inferencing (in cases of emotion-based adaptation) or are directly mapped to the adapted features of the affective game, without any recognition of emotions. Half of the reviewed studies apply directly mapping of threshold values of the measured signals or extracted features to values of the adapted game features, as this is an easy and straightforward way of achieving adaptiveness. As methods for data fusion, emotion inferencing uses either linear estimation or regression methods $[88,91]$, or emotion classification through kNN, SVM, ANN, LDA, BNT and NBC, with classification accuracy being dependent on the method and experimental context and having extreme values for SVM - 53.33\% [83] and 88.9\% [9]. The choice of discrete emotions depends strongly on the primary purpose and the genre of the effective game. On the other hand, many adaptive games use more straightforward approaches of direct mapping of physiological signals correlated to one or several discrete emotions or simply to the arousal level $[34,94]$. Raw signal or its features are mapped to adjusted game properties or features, either by establishing linear dependency between them or by setting signal thresholds for switching on or off given game features.

Classification accuracy depends strongly on the context of executed experiments such as training data set, use of cross-validation, and number of analysed participants (subjects) played the game. Table 3 provides comparison regarding experimental validation, outcomes and impact of the affect-based adaptation. Almost all the studies use quasi-experimental design with repeated treatment approaches having pre-test and post-test measures each time, with exclusion of the study of [10], which applies randomized control trial. For the 14 compared games, the number of subjects varies from 5 [93] up to 75 [87] excluding the first game (although lack of experimental data, it was included here due to its technological merits). Although experiments with too few subjects can bring valuable informative about further research directions, they do not have statistical significance and remain unconvincing [15]. The subject age interval depends on the goal of the study and varies from 8-10 years [16] up to 18-54 years [9] and has mean values $M$ between 19 and 35 and standard deviations SD ranges between 13.0 and 14.8. The gender balance (males to females ratio) is in favour of men $(\mathrm{M}=2.39, \mathrm{SD}=1.39)$ and varies between 0.67 and 4.33. In four of the experiments, subjects have been required to have previous game experience, while in other three experiments various game experience has been 
registered but not required. Repeated treatment approaches imply several play sessions ( $\mathrm{M}=5.17, \mathrm{SD}=6.16)$ playing non-adaptive and adaptive versions of the same game. Each session has lasted from 1.5 up to 10 min. $(\mathrm{M}=3.82, \mathrm{SD}=2.40)$.

The last column of Table 3 provides a summary of the results on the outcome and impact of emotional adaptivity obtained by means of custom questionnaires, GEQ, SAM, UMACL, or other means for self-report. The results obtained by questionnaires demonstrate that the adapted game version creates more fun at the players than the static game [16, 32] and brings better performance of the majority of the participants [9]. What is more, affect-based game adaptation makes gameplay more challenging and more satisfying than performance-based DDA, where the satisfaction index is defined as a sum of the values of challenge, enjoyment, and reported performance appraisal. Combining negative and positive affective feedback types contributes essentially for reaching a higher satisfaction and keeping the player in the flow zone, while avoiding both player's boredom and anxiety. As stated in [83], "the challenge should be corrected to maintain a state of pleasure and involvement, showing the importance of having games that increase their difficulty according to the competence and emotions of the player".

Table 3. Experimental validation, outcomes and impact of the affect-based adaptation

\begin{tabular}{|c|c|c|c|c|c|c|c|c|c|c|c|c|}
\hline No & Study objectives & $\begin{array}{l}\text { Met- } \\
\text { hod }\end{array}$ & $\begin{array}{l}\text { No } \\
\text { sub- } \\
\text { jects }\end{array}$ & Age & $\begin{array}{l}\text { Age } \\
\text { M }\end{array}$ & $\begin{array}{l}\text { Males- } \\
\text { Fema- } \\
\text { les }\end{array}$ & $\begin{array}{l}\text { Gen- } \\
\text { der } \\
\text { bala- } \\
\text { nce }\end{array}$ & $\begin{array}{l}\text { Game } \\
\text { expe- } \\
\text { rience }\end{array}$ & $\mathrm{NG}^{4}$ & $\begin{array}{l}\text { Game } \\
\text { time } \\
(\min )\end{array}$ & $\begin{array}{l}\text { Question- } \\
\text { naires } \\
\text { and inter- } \\
\text { views }\end{array}$ & Results and conclusions \\
\hline 1 & $\begin{array}{l}\text { To apply } \\
\text { physiological } \\
\text { measures for } \\
\text { inferring player's } \\
\text { stress (activation) } \\
\text { and, next, for } \\
\text { dynamic } \\
\text { adjustment of some } \\
\text { game features }\end{array}$ & & & & & & & & & & & $\begin{array}{l}\text { Game adaptation to player's } \\
\text { stress (activation) may lead to } \\
\text { higher immersion, new forms } \\
\text { of focused involvement and, as } \\
\text { well, to new game play } \\
\text { strategies }\end{array}$ \\
\hline 2 & $\begin{array}{l}\text { To study how } \\
\text { appliance of } \\
\text { biometric sensory } \\
\text { devices would } \\
\text { allow incorporation } \\
\text { of player's } \\
\text { biometric } \\
\text { information into a } \\
\text { commercial } \\
\text { computer game for } \\
\text { achieving more } \\
\text { dynamic, } \\
\text { personalized and } \\
\text { situated game } \\
\text { experiences }\end{array}$ & RCT & 14 & $\begin{array}{l}15- \\
50\end{array}$ & & $13-3$ & 4.33 & various & 2 & 5 & $\begin{array}{l}\text { 7q. custom } \\
\text { questionnai } \\
\text { rand post- } \\
\text { session } \\
\text { interview }\end{array}$ & $\begin{array}{l}\text { Evaluation results demonstrate } \\
\text { biometric adaptation can } \\
\text { improve the situated feeling of } \\
\text { horror. While variation of } \\
\text { biometric information between } \\
\text { male was found to be wide, the } \\
\text { same was almost constant for } \\
\text { females. Biometric adaptation } \\
\text { of game mechanics and audio } \\
\text { effects increases player } \\
\text { engagement, but only for these } \\
\text { players who do enjoy the game } \\
\text { genre }\end{array}$ \\
\hline 3 & $\begin{array}{l}\text { To investigate how } \\
\text { changes in game } \\
\text { speed produce } \\
\text { emotional } \\
\text { responces } \\
\text { accompanied by } \\
\text { specific emotion- } \\
\text { data }\end{array}$ & QED & 24 & $\begin{array}{l}23- \\
46\end{array}$ & 29.7 & $19-5$ & 3.80 & yes & 3 & 2 & $\begin{array}{l}\text { Custom } \\
\text { questionnai } \\
\text {-res (incl. } \\
\text { parts of } \\
\text { SAM), } \\
\text { semi- } \\
\text { structured } \\
\text { post-game } \\
\text { interview }\end{array}$ & $\begin{array}{l}\text { Changing game speed inducted } \\
\text { boredom, frustration and } \\
\text { enjoyment, where slow speed } \\
\text { was considered boring and fast } \\
\text { speed was enjoyable for some } \\
\text { players but frustrating for } \\
\text { others. Experimental data } \\
\text { should be further analyzed for } \\
\text { variance, kurtosis and } \\
\text { skewness. For an emotionally } \\
\text { adapted Pacman game, initial } \\
\text { or previous emotional states } \\
\text { should be considered, together } \\
\text { with accurate emotion-data on } \\
\text { flow crossing-border events }\end{array}$ \\
\hline
\end{tabular}

\footnotetext{
${ }^{4}$ Number of played Games (NG)
} 
Table 3 (c on t i n u e d)

\begin{tabular}{|c|c|c|c|c|c|c|c|c|c|c|c|c|}
\hline No & Study objectives & $\begin{array}{l}\text { Met- } \\
\text { hod }\end{array}$ & $\begin{array}{l}\text { No } \\
\text { sub- } \\
\text { jects }\end{array}$ & Age & $\begin{array}{l}\text { Age } \\
\text { M }\end{array}$ & $\begin{array}{l}\text { Males- } \\
\text { females }\end{array}$ & $\begin{array}{l}\text { Gen- } \\
\text { der } \\
\text { Bala- } \\
\text { nce }\end{array}$ & $\begin{array}{l}\text { Game } \\
\text { expe- } \\
\text { rience }\end{array}$ & NG & $\begin{array}{l}\text { Game } \\
\text { time } \\
\text { (min) }\end{array}$ & $\begin{array}{l}\text { Question- } \\
\text { naires } \\
\text { and inter- } \\
\text { views }\end{array}$ & Results and conclusions \\
\hline 4 & $\begin{array}{l}\text { To validate usefulness } \\
\text { of boredom, anxiety, } \\
\text { and engagement by } \\
\text { modulating challenge } \\
\text { by adjusting game } \\
\text { difficulty, where } \\
\text { playing at different } \\
\text { difficulty levels } \\
\text { provokes different } \\
\text { emotional states (H1), } \\
\text { which can be assessed } \\
\text { via central and } \\
\text { peripheral signals } \\
\text { (H2); increasing skills } \\
\text { moves the player } \\
\text { fromengagement to } \\
\text { boredom (H3) }\end{array}$ & QED & 20 & & 27 & $13-7$ & 1.86 & various & 6 & 5 & $\begin{array}{l}30 \mathrm{q} . \\
\text { custom } \\
\text { question- } \\
\text { nair about } \\
\text { emotions } \\
\text { and involv- } \\
\text { ment, } \\
\text { SAM }\end{array}$ & $\begin{array}{l}\text { Player engagement may } \\
\text { decrease if game difficulty is } \\
\text { not modulated for a longer } \\
\text { period. Player disengagement } \\
\text { in hard conditions should be } \\
\text { solved increasing challange } \\
\text { according detectedemotion, } \\
\text { current level of difficulty and } \\
\text { the direction of its last change. } \\
\text { Analysis of measured signals } \\
\text { should be conducted not only } \\
\text { for the complete session time, } \\
\text { but on an event basis }\end{array}$ \\
\hline 5 & $\begin{array}{l}\text { To demonstrate how a } \\
\text { subjective model of } \\
\text { reported entertainment } \\
\text { using statistical } \\
\text { features derived from } \\
\text { player's physiological } \\
\text { state can be applied } \\
\text { for modulation of } \\
\text { game parameters in } \\
\text { order to enhance } \\
\text { player satisfaction }\end{array}$ & QED & 72 & $8-10$ & & $13-11$ & 1.18 & no & 4 & 1.5 & $\begin{array}{l}4 \\
\text { alternative } \\
\text { forced } \\
\text { choice } \\
\text { (4AFC) } \\
\text { protocol }\end{array}$ & $\begin{array}{l}\text { Real-time adaptation can } \\
\text { significantly increasy } \\
\text { entertainment value of a game } \\
\text { for children. At the same time, } \\
\text { individual differences } \\
\text { regarding preferences and } \\
\text { playing behavior make inter- } \\
\text { subject generalization not } \\
\text { possible and, thus, limit the } \\
\text { predictive ability of player } \\
\text { models. As well, erroneous } \\
\text { adjustments of levels of both } \\
\text { curiosity and challenge within } \\
\text { the game may have an } \\
\text { influence on preference of } \\
\text { children for adaptation }\end{array}$ \\
\hline 6 & $\begin{array}{l}\text { To analyse player's } \\
\text { physiological signals } \\
\text { in order to infer } \\
\text { anxiety level and to } \\
\text { study how it can be } \\
\text { used as target affective } \\
\text { state forDDA of } \\
\text { game in real time }\end{array}$ & QED & 15 & $\begin{array}{l}18- \\
54\end{array}$ & & $8-7$ & 1.14 & yes & 24 & 2 & $\begin{array}{l}\text { Anxiety } \\
\text { self-report }\end{array}$ & $\begin{array}{l}\text { RT classifier demonstrated } \\
\text { highest accuracy in predicting } \\
\text { player's anxiety level. Most } \\
\text { participants perceived the } \\
\text { gameplay with the affect- } \\
\text { based DDA to be more } \\
\text { challenging and satisfying } \\
\text { than the one with } \\
\text { performance-based DDA }\end{array}$ \\
\hline 7 & $\begin{array}{l}\text { To determine if fNIR } \\
\text { biomarkers of neural } \\
\text { activity, which are } \\
\text { generated by } \\
\text { intentional cognitive } \\
\text { activity, can be } \\
\text { applied to indicate } \\
\text { directly the brain effort } \\
\text { within an ecologically } \\
\text { valid environment } \\
\text { using compelling } \\
\text { brain-computer } \\
\text { intefaces for game } \\
\text { design }\end{array}$ & QED & 5 & $\begin{array}{l}24 \\
27\end{array}$ & & 41 & 4.00 & no & 1 & 2.83 & $\begin{array}{l}\text { Effor self- } \\
\text { assessment } \\
\text { screen } \\
(0-10)\end{array}$ & $\begin{array}{l}\text { The success rate of } \\
\text { classification algorithms varies } \\
\text { between subjects revealing the } \\
\text { fact subjects use closed loop } \\
\text { systems in different ways. } \\
\text { Future brain research needs } \\
\text { incorporation of more players } \\
\text { with emphasis on team work } \\
\text { in order to analyze not only } \\
\text { individual but group dynamic, } \\
\text { as well. Game sessions can be } \\
\text { played most effectively in } \\
\text { online game environments } \\
\text { allowing better control of data } \\
\text { acquisition and user feedback }\end{array}$ \\
\hline 8 & $\begin{array}{l}\text { To developa } \\
\text { methodological } \\
\text { framework for } \\
\text { estimation of player's } \\
\text { preference among } \\
\text { racing game } \\
\text { experiences using } \\
\text { player's physiological } \\
\text { state }\end{array}$ & QED & 75 & $\begin{array}{l}18- \\
30\end{array}$ & 23.4 & $60-15$ & 4.00 & various & 7 & 3 & $\begin{array}{l}\text { General } \\
\text { question- } \\
\text { naire and } \\
\text { enjoyment } \\
\text { preference } \\
\text { 2-AFC } \\
\text { question- } \\
\text { naire }\end{array}$ & $\begin{array}{l}\text { Only } 42 \% \text { of subjects had } \\
\text { consistent agreement on } \\
\text { preferring opponent as skilled } \\
\text { as the player. Ths, game } \\
\text { preference shold be regarded } \\
\text { as a personal issue, therefore, it } \\
\text { is hard to design a priori game } \\
\text { experience (e.g., by changing } \\
\text { opponent skills) that appears } \\
\text { to match needs of all the } \\
\text { players. Further experiments } \\
\text { should modify game } \\
\text { experience in real time in } \\
\text { order to keepplayer } \\
\text { satisfaction to a high level }\end{array}$ \\
\hline
\end{tabular}




\begin{tabular}{|c|c|c|c|c|c|c|c|c|c|c|c|c|}
\hline $\mathrm{N}$ & Study objectives & $\begin{array}{l}\text { Met- } \\
\text { hod }\end{array}$ & $\begin{array}{l}\text { No } \\
\text { sub- } \\
\text { jects }\end{array}$ & Age & $\begin{array}{l}\text { Age } \\
\text { M }\end{array}$ & $\begin{array}{l}\text { Males- } \\
\text { females }\end{array}$ & $\begin{array}{l}\text { Gender } \\
\text { balance }\end{array}$ & $\begin{array}{l}\text { Game } \\
\text { expe- } \\
\text { rience }\end{array}$ & NG & $\begin{array}{l}\text { Game } \\
\text { time } \\
\text { (min) }\end{array}$ & $\begin{array}{l}\text { Questio- } \\
\text { nnaires } \\
\text { and inter- } \\
\text { views } \\
\end{array}$ & Results and conclusions \\
\hline 9 & $\begin{array}{l}\text { To study how direct } \\
\text { and indirect } \\
\text { physiological sensor } \\
\text { input can be applied } \\
\text { to augment traditional } \\
\text { game control and to } \\
\text { find out best mapping } \\
\text { between measured } \\
\text { signals and game } \\
\text { mechanics }\end{array}$ & QED & 10 & $\begin{array}{l}21- \\
40\end{array}$ & 25.8 & $7-3$ & 2.33 & yes & 3 & 10 & $\begin{array}{l}\text { Demograp } \\
\text { hics } \\
\text { questionna } \\
\text { ire and } \\
\text { game-play } \\
\text { experience } \\
\text { survey }\end{array}$ & $\begin{array}{l}\text { Physiological augmentation of } \\
\text { game interaction creates better } \\
\text { fun experience than traditional } \\
\text { game control. Participants do } \\
\text { prefer direct (rather than } \\
\text { indirect) physiological control in } \\
\text { games because of its visible } \\
\text { responsiveness when mapped } \\
\text { intuitively to reflect actions in } \\
\text { the virtual world. Indirect } \\
\text { physiological input serves better } \\
\text { for modifying passive reactions } \\
\text { and peripheral features of the } \\
\text { game world }\end{array}$ \\
\hline 10 & $\begin{array}{l}\text { To investigate ways } \\
\text { of "constructing a } \\
\text { biocybernetic loop } \\
\text { that is both } \\
\text { scientifically valid and } \\
\text { effective from the } \\
\text { perspective of user } \\
\text { experience", namely } \\
\text { conservative, liberal, } \\
\text { normal and manual } \\
\text { game agjustment } \\
\text { according to EEG } \\
\text { deviations from } \\
\text { baseline }\end{array}$ & QED & 10 & & & 46 & 0.67 & no & 4 & 5 & $\begin{array}{l}\text { UMACL } \\
\text { and } \\
\text { immersion } \\
\text { question- } \\
\text { naire }\end{array}$ & $\begin{array}{l}\text { Experimental results showed } \\
\text { biocybernetic game playing } \\
\text { experiences in conservative } \\
\text { mode have an enhanced } \\
\text { alertness compared to the libera } \\
\text { mode. On other hand, players } \\
\text { repoted the manual game } \\
\text { mode as more immersive than } \\
\text { the others, that was explained } \\
\text { by optimal level of challenge } \\
\text { provided in manual mode }\end{array}$ \\
\hline 11 & $\begin{array}{l}\text { To demonstrate how } \\
\text { a custom wearable } \\
\text { EEG-based device } \\
\text { withdry EEG sensors } \\
\text { canbe used for } \\
\text { cognitive state } \\
\text { monitoring within } \\
\text { adaptive gaming }\end{array}$ & QED & 10 & $\begin{array}{l}24 \\
27\end{array}$ & & & & no & & & & $\begin{array}{l}\text { Experimental results proved } \\
\text { that the focus feature of EEG } \\
\text { alphar rhythm is a reliable } \\
\text { indicator of player focus state. } \\
\text { The proposed algorithm for } \\
\text { measuring user focus level can } \\
\text { be useful not only for short-term } \\
\text { memory tasks, but for long- } \\
\text { termactivities, as well }\end{array}$ \\
\hline 12 & $\begin{array}{l}\text { To study different } \\
\text { models of adjustment } \\
\text { of game mechanics } \\
\text { combined with direct } \\
\text { and indirect } \\
\text { biofeedbacks }\end{array}$ & QED & 24 & $\begin{array}{l}19- \\
28\end{array}$ & 22.5 & $16-8$ & 2.00 & yes & 3 & 1.5 & $\begin{array}{l}\text { Arousal } \\
\text { and } \\
\text { valence, } \\
\text { GEQ, } \\
\text { biofeed- } \\
\text { back } \\
\text { condition }\end{array}$ & $\begin{array}{l}\text { There was created and } \\
\text { experimentaly tested a robust } \\
\text { and completely game- } \\
\text { independent framework of an } \\
\text { indirect biofeedback system. It } \\
\text { was proven the framework } \\
\text { "contributes significantly to the } \\
\text { player affection towards the } \\
\text { game" }\end{array}$ \\
\hline 13 & $\begin{array}{l}\text { To model interactions } \\
\text { between player } \\
\text { arousal derived by } \\
\text { physiological } \\
\text { measures and game } \\
\text { difficulty as a control } \\
\text { problemusing } \\
\text { proportional and } \\
\text { proportional-integral- } \\
\text { derivative control, and } \\
\text { to validate the } \\
\text { approach by adapting } \\
\text { game mechanics of a } \\
\text { car-racing game in } \\
\text { real time } \\
\end{array}$ & QED & 25 & $\begin{array}{l}18- \\
33\end{array}$ & & & & no & 2 & 5 & & $\begin{array}{l}\text { Authors found speed adaptation } \\
\text { is more effective than the other } \\
\text { two mechanics and, as well, } \\
\text { between the two control modes } \\
\text { They proved proportional- } \\
\text { integral-derivative control } \\
\text { results in impreved adaptation } \\
\text { and decreased oscillations in a } \\
\text { loop with negative feadback } \\
\text { compared to proportional-only } \\
\text { control }\end{array}$ \\
\hline 14 & $\begin{array}{l}\text { To study whethera } \\
\text { biofeedback version } \\
\text { of the Pong game } \\
\text { would improve user } \\
\text { experience and } \\
\text { performance } \\
\text { compared to the non- } \\
\text { adaptive version }\end{array}$ & QED & 8 & & & 44 & 1.00 & no & 3 & 3 & $\begin{array}{l}\text { Custom } \\
\text { questionna } \\
\text { ire about } \\
\text { game } \\
\text { experience }\end{array}$ & $\begin{array}{l}\text { Experimental results } \\
\text { demonstrated that physiological } \\
\text { data leads to an improved user } \\
\text { experience, however, user } \\
\text { performance within a two- } \\
\text { players gameplay remains the } \\
\text { same with applying } \\
\text { biofeedback. Further studies } \\
\text { should investigate the difference } \\
\text { between displaying and not } \\
\text { showing the physiological } \\
\text { player's state in the game }\end{array}$ \\
\hline
\end{tabular}




\section{Conclusion}

Since its advent in the end of the last century, affective computing has never stopped being attractive and challenging for researchers, engineers and software developers who try to create emotionally-based applications and products. As discussed above, there are reported many experimental approaches for inferring user emotions according to measured physiological signals. Model-based approaches derived from theoretical frameworks for mapping player's modalities to emotional state can be confronted to model-free approaches accepting that mapping is unknown and using either a statistical model, a static or a dynamic machine learning for discovering the mapping function and inferring emotions according to input modalities [19]. The majority of adaptive physiological systems use static data fusion methods [29], where machine learning methods are employed for training and cross-validation, which are performed once and in advance to the system adaptation. To a large extent, this is determined by the fact that software applications for automatic classification such as IBM SPSS do not allow online application. On the other hand, dynamic data fusion systems learn on-the-fly or analyse history of the measured signals and extracted features.

Though there are at present plenty of affective research papers in the context of video games, relatively few of them really apply recognized emotions for adapting some game features and properties in real time. The creation of precise models describing player behaviour and applying them practically during both controlled and uncontrolled gameplay is crucial for accurate recognition of emotions and, therefore, for an effective affect-based adaptation of entertainment games or applied games for technology-enhanced learning [98]. In order to deal with the manifestation of affect specific for any individual player, affective behavioural models should include a real time learning module for tracking the behaviour of the player and extracting and analysing available affective patterns [11]. Thus, such player models will accumulate valuable information about affective state of the player by using direct observations and will be able to monitor the player's behaviour in an effective way, and even to predict it. Such predictive models can be based on ANN for relating game features regarding mechanics, dynamics and aesthetics of the game, to entertainment values like fun, curiosity and challenge [16]. Dynamic models of player behaviour focused on tracking and monitoring of player interactions can be used for both recognition of player's emotions and inducing appropriate emotions during gameplay. What is more, they can be applied for generation of emotional NPC's appropriate for specific player's behaviour.

The affective player models can include various strategies for adjusting game features according to physiological state of the player in real time. Besides player's responses from ANS and CNS activity (physiological modality) and behavioural expressions like face grimaces, speech and gesture (expressive modality), adaptation strategies should take into account other player's modalities such as cognitive (interpretive) modality concerning appraisal aspects of emotion generation and, as well, experiential (subjective) modality dealing with conscious emotional experiences of individual users [45]. The complex, multi-modal nature of human 
emotions supposes that all types of emotion signatures should be detected and analyses all of them together, however, not all of them rely on non-obtrusive and appropriate measuring methods. For example, emotion recognition using facial expression will have a worse accuracy if the user is not still or inclined to the screen more or less than the required angle [73]. What is more, standard sensors such as fixed finger-tip caps for measuring GSR or HRV are less appropriate for active game play than wireless and wearable sensors [30] allowing physical contact with the body by being incorporated in gloves, shoes, glasses, helmets or other accessories. Finally, seamless contact sensors incorporated into traditional devices like computer mouse are very promising and much more appropriate for an advanced multi-modal biometric recognition of emotions.

Until recently, adaptation mechanisms have been mainly explored in affective games using single-player mode because it creates less variability and potential problems with influencing player reaction by collaboration with other players [10]. Experiments with adaptive multi-player games may reveal interesting phenomena of dependencies between DDA and biometric responses of individual players in context of cooperative gameplay. Emotional-based adaptation may produce a different effect on the player depending on showing and hiding player's physiological state in single player mode [94] or in a multi-player gameplay, which can make the player realizing better the adaptation mechanism and starting to control his/her physiological changes. In general, future research should investigate various ways for augmenting gaming experience through recognition of player's affective state and applying it for dynamic adaptation of game features.

Affective gaming has not yet gained enough popularity among the casual gamers and remains mostly restricted to laboratory experiments [15]. Latest developments in the area of affect-adaptive gaming pave the way from controlled and restricted laboratory experiments proving both the desirability and effectiveness of adjusting game features according to player's affect, to commercial entertainment and serious video games with emotion-based adaptation. Further research in affectbased adaptation should envisage more realistic and complete modelling and profiling for monitoring strategic and tactical player behaviour, providing a basis for multi-modal affective gaming with enhanced adaptation and representation of game environment, player's avatar and NPC's in the game. Future adaptive affective video games are expected to use appropriate and affordable sensors and devices, and to have proven ecological validity in more statistically representative field trials maximally closed to everyday game play.

Acknowledgements: The research leading to these results has received funding from the People Programme (Marie Curie Actions) of the European Union's Seventh Framework Programme FP7 (2007-2013) under REA grant agreement No 624184

\section{References}

1. P i c a rd, R. W. Affective Computing. MIT Media Laboratory Perceptual Computing Section, Technical Report No 321, 1995.

http://affect.media.mit.edu/pdfs/95.picard.pdf 
2. W a t s o n, D., L. C l a rk, A. Te 11 e ge n. Development and Validation of Brief Measures of Positive and Negative Affect: The PANAS Scales. - J. of Pers. and Social Psych., Vol. 47, 1988, pp. 1063-1070.

3. S c h w a r t z, M. S. Biofeedback: A Practioner's Guide. New York, Guilford Press, 1995.

4. Bersak, D., G. McDarby, N. Augenblick, P. McDarby, D. McDonnell, B. M c D o n a ld, R. K a r k u n. Intelligent Biofeedback Using an Immersive Competitive Environment. - In: Proc. of Designing Ubiquitous Computing Games Workshop, UbiComp, Atlanta, USA, September, 2001.

5. Pope, A. T., E. H. B o gart, D. S. B a r to lo m e. Biocybernetic System Evaluates Indices of Operator Engagement in Automated Task. - Biological Psychology, Vol. 40, 1995, pp. 187-195.

6. Cole s, M., M. Ru g g. Event-Related Brain Potentials: An Introduction. - Electrophysiology of Mind, Oxford Scholarship Online Monographs, 1996, pp. 1-27, http://13d.cs.colorado.edu/ ctg/classes/lib/cogsci/Rugg-ColesChp1.pdf

7. M a u s s, I. B., M. D. R o b i n s o n. Measures of Emotion: A Review. - Cognition and Emotion, Vol. 23, 2009, No 2, pp. 209-237.

8. Kreibig, S. D. Autonomic Nervous System Activity in Emotion: A Review. - Biological Psychology, Vol. 84, 2010, pp. 394-421.

9. Li u, C., P. A grawa 1, N. S a rk a r, S. Chen. Dynamic Difficulty Adjustment in Computer Games through Real-Time Anxiety-Based Affective Feedback. - Int. J. Hum. Comput. Interact., Vol. 25, 2009, pp. 506-529.

10. D e k k e r, A., E. C h a m p i o n. Please Biofeed the Zombies: Enhancing the Gameplay and Display of a Horror Game Using Biofeedback. - In: Proc. of DiGRA 2007, Tokyo, Japan, 2007, pp. 550-558.

11. H u d li cka, E. Affective Computing for Game Design. - In: Proc. of 4th Int. North American Conf. on Intelligent Games and Simulation (GAMEON-NA), Montreal, Canada, 2008, pp. 5-12.

12. Gigg i n s, O. M., U. M. P e r s s o n, B. C a u $1 \mathrm{fi}$ e 1 d. Biofeedback in Rehabilitation. - J. of Neuroengineering and Rehabilitation, Vol. 10, 2013, No 60. DOI: 10.1186/1743-0003-10-60.

13. Gill e a d e, K., A. D i x, J. A 11 a n s o n. Affective Videogames and Modes of Affective Gaming: Assist Me, Challenge Me, Emote Me. - In: Proc. of DiGRA Conf.: Changing Views - Worlds in Play, 2005.

14. S w e e t s e r, P., P. W y e th. GameFlow: A Model for Evaluating Player Enjoyment in Games. Computers In Entertainment (CIE), Vol. 3, 2005, No 3, pp. 3-3.

15. Kivikangas, J. M., G. Ch an e 1, B. Cow le y, I. Ekm a n, M. S a l mi ne n, S. Järvelä, N. R a vaja. A Review of the Use of Psychophysiological Methods in Game Research. Journal of Gaming \& Virtual Worlds, Vol. 3, 2011, No 3, pp. 181-199.

16. Y a n n a k a ki s, G. N., J. H a 11 a m. Entertainment Modeling through Physiology in Physical Play. - Int. Journal of Human-Computer Studies, Vol. 66, 2008, No 10, pp. 741-755.

17. A m b i n d e r, M. Biofeedback in Gameplay: How Valve Measures Physiology to Enhance Gaming Experience. Valve Software, 2011. http://www.valvesoftware.com/publications/2011/Valve Biofeedback-Ambinder.pdf

18. Hö ö k, K. Affective Loop Experiences-What Are They? - Berlin, Heidelberg, Persuasive Technology, Springer, 2008, pp. 1-12.

19. Y a n $\mathrm{n}$ a k a k i s, G. N., J. T o g e $\mathrm{l}$ i u s. Experience-Driven Procedural Content Generation. - IEEE Transactions on Affective Computing, Vol. 2, 2011, No 3, pp. 147-161.

20. Fairclough, S., K. Gille ad e. Construction of the Biocybernetic Loop: A Case Study. In: Proc. of 14th ACM Int. Conf. on Multimodal Interaction, ACM, October 2012, pp. 571-578.

21. Murphy, C., D. Chertoff, M. Guerrero, K. Moffitt. Design Better Games: Flow, Motivation, and Fun. - In: Design and Development of Training Games: Practical Guidelines from a Multidisciplinary Perspective (Chapter 5). Cambridge University Press, 2013, p.1773.

22. S w e e t s e r, P., D. M. J o h n s o n, P. W y e th. Revisiting the GameFlow Model with Detailed Heuristics. - Creative Technologies, 2012, No 3. 
23. R a n i, P., N. S a r k a r, C. L i u. Maintaining Optimal Challenge in Computer Games through RealTime Physiological Feedback. - In: Proc. of 11th Int. Conf. on Human Comp. Interact., 2005, pp. 184-192.

24. Grigore, O., I. Gavat, M. Cotes c u, C. Grigore. Stochastic Algorithms for Adaptive Lighting Control Using Psycho-Physiological Features. - Int. J. of Biology and Biomedical Eng., Vol. 2, 2008, pp. 9-18.

25. B akkes, S., C. T. Ta n, Y. P i s a n. Personalised Gaming: A Motivation and Overview of Literature. - In: Proc. of 8th Australas. Conf. on Interact. Entertainm.: Playing the System, ACM, 2012, p. 4.

26. K i c k m e i e r-R u s t, M. D., D. A 1 b e r t. Educationally Adaptive: Balancing Serious Games. Int. Journal of Computer Science in Sport, Vol. 11, 2012, No 1, pp. 1-10.

27. Ch a n g, D. M. J. Dynamic Difficulty Adjustment in Computer Games. - In: Proc. of 11th Ann. Interact. Multimedia Systems Conf., Univ. of Southampton, UK, 2013. http://mms.ecs.soton.ac.uk/2013/papers/dmjc1g10_23990287_finalpaper.pdf

28. F a i r c lo u g h, S. H. Fundamentals of Physiological Computing. - Interacting with Computers, Vol. 21, 2009, No 1, pp. 133-145.

29. Novak, D., M. Mihelj, M. Munih. A Survey of Methods for Data Fusion and System Adaptation Using Autonomic Nervous System Responses in Physiological Computing. Interacting with Computers, Vol. 24, 2012, pp. 153-172.

30. C h r i s t y, T., L. I. K u n c h e v a. Technological Advancements in Affective Gaming: A Historical Survey. - GSTF Journal on Computing, Vol. 3, 2014, No 4.

31. R o u s e, R. Games on the Verge of a Nervous Breakdown: Emotional Content in Computer Games. - ACM SIGGRAPH Computer Graphics, Vol. 35, 2001, No 1, pp. 6-10.

32. N a c k e, L. E., M. K a l y n, C. L o u g h, R. L. M a n d r y k. Biofeedback Game Design: Using Direct and Indirect Physiological Control to Enhance Game Interaction. - In: Proc. of SIGCHI Conf. on Human Factors in Computing Systems, ACM, 2011, pp. 103-112.

33. Ku i k k an i e mi, K., T. La it in e n, M. Turpeinen, T. S a ari, I. Ko s un en, N. R a vaja. The Influence of Implicit and Explicit Biofeedback in First-Person Shooter Games. - In: Proc. of SIGCHI Conf. on Human Factors in Computing Systems, 2010, pp. 859-868.

34. P a r n a n d i, A., R. G u t i e r r e z-O s u n a. A Comparative Study of Game Mechanics and Control Laws for an Adaptive Physiological Game. - J. on Multimodal User Interfaces, 2014, pp. 1-12.

35. Li in d l e y, C. A., C. C. S e n n e r s t e n. Game Play Schemas: from Player Analysis to Adaptive Game Mechanics. - In: Proc. of Int. Conf. on Game Research and Development, 2006, pp. 47-53.

36. Gi 11 e a d e, K. M., A. D i x. Using Frustration in the Design of Adaptive Videogames. - In: Proc. of ACM SIGCHI Int. Conf. on Advances in Computer Entertainment Technology, 2004, pp. 228-232.

37. Tre m b l a y, J., C. V e r b r u g g e. Adaptive Companions in FPS Games. - FDG, Vol. 13, 2013, pp. 229-236.

38. Ch e n, J. Flow in Games (and Everything Else). - Communications of the ACM, Vol. 50, 2007, No 4, pp. 31-34.

39. Garne r, T. A. Game Sound from Behind the Sofa: An Exploration into the Fear Potential of Sound\&Psychophysiological Approaches to Audio-Centric, Adaptive Gameplay. PhD Thesis, Aalborg University, 2013.

40. H u n i cke, R., V. Ch a p man. AI for Dynamic Difficulty Adjustment in Games. - In: Proc. of Challenges in Game Artificial Intelligence AAAI Workshop, Vol. 2, 2004, p. 1.

41. K o s t e r, R. A Theory of Fun for Game Design. Paraglyph Press, 2005.

42. Y annakakis, G. N., A. P a iva. Emotion in Games. - Handbook on Affective Computing, Vol. 20, 2013.

43. B risson, A., G. Pereira, R. Prada, A. Paiva, S. Louchart, N. Suttie, T. Lim, R. Lopes, R. Bidarra, F. Bellotti, M. Kravcik, M. Oliveira. Artificial Intelligence and Personalization Opportunities for Serious Games. - In: Proc. of 8th AIIDE Conf., 2012, pp. 51-57. 
44. B a k ke s, S., P. S pron c k, J. V a n D e n H e rik. Rapid and Reliable Adaptation of Video Game AI. - IEEE Transactions on Computational Intelligence and AI in Games, Vol. 1, 2009, No 2, pp. 93-104.

45. H u d li c k a, E. Affective Game Engines: Motivation and Requirements. - In: Proc. of 4th Int. Conf. on Foundations of Digital Games, ACM, 2009, pp. 299-306.

46. E k m a n, P., E. R. S or e n s o n, W. V. Fri e s e n. Pan-Cultural Elements in Facial Displays of Emotion. - Science, Vol. 164, 1969, No 3875, pp. 86-88. DOI:10.1126/science.164.3875.86.

47. H u p o n t, I., S. B a ld a s s a r ri, E. C e r e z o. Facial Emotional Classification: From a Discrete Perspective to a Continuous Emotional Space. - Pattern Analysis and Applications, Vol. 16, 2013, Issue 1, pp. 41-54. DOI: 10.1007/s10044-012-0286-6.

48. T a n, C. T., S. B a k ke s, Y. P is a n. Inferring Player Experiences Using Facial Expressions Analysis. - In: Proc. of Conf. on Interactive Entertainment, ACM, New York, USA, 2014, pp. 1-8.

49. K a p l a n, S., R. S. D a 1 a 1, J. N. L u c h m a n. Measurement of Emotions. Research Methods in Occupational Health Psychology. New York, Routledge, 2013.

50. $\mathrm{McCr}$ a e, R. R., P. C. Costa. Validation of the Five-Factor Model Across Instruments and Observers. - Journal of Personality and Social Psychology, Vol. 52, 1987, pp. 81-90.

51. R u s s e 11, J. A. A Circumplex Model of Affect. - Journal of Personality and Social Psychology, Vol. 39, 1980, No 6, pp. 1161-1178.

52. M e n d 1, M., O. H. P. B u r m a n, E. S. P a u l. An Integrative and Functional Framework for the Study of Animal Emotion and Mood. - In: Proc. Biol. Sci., Vol. 277, 2010, pp. 2895-2904.

53. Trim m e r, P. C., E. S. P a u l, M. T. Mend l, J. M. M c N a m a r a, A. I. H o u s to n. On the Evolution and Optimality of Mood States. - Behav. Sci., Vol. 3, 2013, pp. 501-521.

54. M e h r a b i a n, A., J. A. R u s s e 11. An Approach to Environmental Psychology. Cambridge, MA, USA; London, UK: MIT Press, 1974.

55. Gunes, H., B. S chuller, M. Pantic, R. Cowie. Emotion Representation, Analysis and Synthesis in Continuous Space: A Survey. - In: Proc. of IEEE Int. Conf. FG'2011, 2011, pp. 827-834.

56. Csikszentmihalyi, M. Flow: The Psychology of Optimal Experience. London, Harper Perennial, 1990.

57. C s i ks zentmih a ly i, M. Finding Flow: The Psychology of Engagement with Everyday Life. New York, BasicBooks, 1997.

58. W u, M. Gamification 101: The Psychology of Motivation, Science of Social Blog. Lithium, 2012. https://community.lithium.com/t5/Science-of-Social-blog/Gamification-101-ThePsychology-of-Motivation/ba-p/21864

59. B r o w n, E., P. C a i r s s. A Grounded Investigation of Game Immersion. - In: CHI'04 Extended Abstracts on Human Factors in Computing Systems, ACM, 2004, pp. 1297-1300.

60. N a c k e, L., C. L i n d l e y. Flow and Immersion in First-Person Shooters: Measuring the Player's Gameplay Experience. - In: Proc. of FuturePlay, 3-5 November 2008, Toronto, Canada, 2008, pp. 81-88.

61. R y a n, R. M., C. S. Rig b y, A. Pr z y b y 1 s ki. The Motivational Pull of Videogames: A SelfDetermination Approach. - Motivation and Emotion, Vol. 30, 2006, pp. 347-363.

62. B r a d l e y, M. M., P. J. L a n. Measuring Emotion: The Self-Assessment Manikin and the Semantic Differential. - Journal of Behavior Therapy and Experimental Psychiatry, Vol. 25, 1994, pp. 49-59.

63. T i j s, T., D. B r o k k e n, W. I j s s e 1 s t e i j n. Creating an Emotionally Adaptive Game. - In: Proc. of ICEC'2008, LNCS 5309, Berlin, Heidelberg, Springer, 2008, pp. 122-133.

64. B r o e ke n s, J., W. P. B r in kman. AffectButton: A Method for Reliable and Valid Affective Self-Report. - Int. Journal of Human-Computer Studies, Vol. 71, 2013, No 6, pp. 641-667.

65. Partala, T., A. Kallinen. Understanding the Most Satisfying and Unsatisfying User Experiences: Emotions, Psychological Needs, and Context. - Interacting with Computers, Vol. 24, January 2012, Issue 1, pp. 25-34.

66. B rockm ye r, J. H., C. M. Fox, K. A. Curtis s, E. Mc B room, K. M. B urkhart, J. N. Pidruzny. The Development of the Game Engagement Questionnaire: A Measure of Engagement in Video Game-Playing. - J. of Experimental Social Psychology, Vol. 45, 2009, No 4, pp. 624-634. 
67. Mat the w s, G., D. M. J on e s, A. G. Ch a mberla i n. Refining the Measurement of Mood: The UWIST Mood Adjective Checklist. - British Journal of Psychology, Vol. 81, 1990, pp. 17- 42 .

68. B a r t l e t t, M. S., J. C. H a g e r, P. E k m a n, T. J. S e j n o w s k i. Measuring Facial Expressions by Computer Image Analysis. - Psychophysiology, Vol. 36, March 1999, No 2, pp. 253-263.

69. $\mathrm{Xu}$, Y., A. K. R o y-Chowdhu ry. Integrating Motion, Illumination and Structure in Video Sequences with Applications in Illumination-Invariant Tracking. - IEEE Transactions on Pattern Analysis and Machine Intelligence, Vol. 29, May 2007, No 5, pp. 793-806.

70. E k m a n, P., W. V. Fri e s e n, J. C. H a ge r. Facial Action Coding System. - A Human Face, Vol. 48, 2002, pp. 4-5.

71. J a c k, R. E. Culture and Facial Expressions of Emotion. - Visual Cognition, Vol. 21, 2013, No 9-10, pp. 1248-1286. DOI:10.1080/13506285.2013.835367.

72. T ang, H., T. Hu ang. 3D Facial Expression Recognition Based on Automatically Selected Features. - In: Proc of IEEE Int. Conf. on Computer Vision and Pattern Recognition, 2008, pp. 1-8.

73. B lo m, P. M., S. B a k ke s, C. T. T a n, S. Wh it e s o n, D. R o i jer s, R. V al en ti, T. Ge vers. Towards Personalised Gaming via Facial Expression Recognition. - In: Proc. of 10th Ann. AAAI Conf. on AIIDE, 2014, pp. 30-36.

74. J a c k, R. E., O. G. Garrod, H. Y u, R. C a ldara, P. G. S ch yn s. Facial Expressions of Emotion Are Not Culturally Universal. - Proc. of Nat. Academy of Sciences, Vol. 109, 2012, No 19 , pp. 7241-7244.

75. P i c a r d, R. W., E. V y z a s, J. H e a le y. Toward Machine Emotional Intelligence: Analysis of Affective Physiological State. - IEEE Trans. Pattern Anal. Mach. Intell., Vol. 23, 2001, No 10, pp. 1175-1191.

76. Mc Craty, R., F. Sh a f fer. Heart Rate Variability: New Perspectives on Physiological Mechanisms, Assessment of Self-Regulatory Capacity, and Health Risk. - Glob. Adv. Health Med., Vol. 4, January 2015, No 1, pp. 46-61. DOI: 10.7453/gahmj.2014.073.

77. B e rn t s o n, G. G., J. T. B igger, D. L. Eckberg, P. Gros s man, P. G. K a u f m a n n, M. Malik, H. N. Nag araja, S. W. Porges, J. P. S a ul, P. S tone, M. V an Der Molen. Heart Rate Variability: Origins, Methods, and Interpretive Caveats. Psychophysiol., Vol. 34, 1997, pp. 623-648.

78. Chit t a r o, L., R. S i on i. Affective Computing vs. Affective Placebo: Study of a BiofeedbackControlled Game for Relaxation Training. - Int. J. of Human-Computer Studies, Vol. 72, 2014 , Issue 8-9, pp. 663-673. DOI:10.1016/j.ijhcs.2014.01.007.

79. B o u c s e i n, W. Electrodermal Activity. Second Ed. New York, USA, Springer, 2006.

80. B r o e k, E. L. V a n D e r, J. H. J a n s s e n, J. H. W e s t e r in k, J. A. H e a l e y. Prerequisites for Affective Signal Processing (ASP). Technical Report, 2009.

81. M e r l e t t i, R., P. A. P a r k e r. Electromyography: Physiology, Engineering, and Non-Invasive Applications. John Wiley \& Sons, 2004.

82. H e a l e y, J. A., R. W. P i c a r d. StartleCam: A Cybernetic Wearable Camera. - In: Proc. of ISWC 1998, IEEE Computer Society, Washington, DC, USA, 1998, pp. 1-8.

83. Ch an e 1, G., C. R e be te z, M. B é tra n c ourt, T. P u n. Boredom, Engagement and Anxiety as Indicators for Adaptation to Difficulty in Games. - In: Proc. of 12th Int. Conf. on Entertainment and Media in the Ubiquitous Era, ACM, 2008, pp. 13-17.

84. Li a o, L. D., C. Y. Ch en, I. J. W a n g, S. F. Ch en, S. Y. Li, B. W. Ch en, J. Y. Ch a n g, C. T. Li in. Gaming Control Using a Wearable and Wireless EEG-Based Brain-Computer Interface Device with Novel Dry Foam-Based Sensors. - J. of Neuroeng. and Rehabilitation, Vol. 9, 2012, No 1, p. 5.

85. D a 1 e, A. M., M. I. S e r e n o. Improved Localization of Cortical Activity by Combining EEG and MEG with MRI Cortical Surface Reconstruction: A Linear Approach. - J. of Cognitive Neuroscience, Vol. 5, 1993, No 2, pp. 162-176.

86. A yaz, H., P. A. Shewokis, S. Bunce, M. S chultheis, B. On aral. Assessment of Cognitive Neural Correlates for a Functional Near Infrared-Based Brain Computer Interface System. - In: Augmented Cognition, HCII 2009, Berlin, Heidelberg, Springer, LNAI 5638, 2009, pp. 699-708. 
87. Tognetti, S., M. Garbarino, A. B o narini, M. Mat te u c ci. Modeling Enjoyment Preference from Physiological Responses in a Car Racing Game. - In: Proc. of IEEE Symp. on Computational Intelligence and Games (CIG’2010), 2010, pp. 321-328.

88. N o g u e ir a, P. A., R. R o d rig u e s, E. Oli ve ir a. Real-Time Psychophysiological Emotional State Estimation in Digital Gameplay Scenarios. - Engineering Applications of Neural Networks, Springer Berlin Heidelberg, 2013, pp. 243-252.

89. M a n d r y k, R. L., M. S. A t k in s. A Fuzzy Physiological Approach for Continuously Modeling Emotion During Interaction with Play Technologies. - Int. J. Hum. Comput. Stud., Vol. 65, 2007, No 4, pp. 329-347.

90. D i c h e v, C., D. D i c h e v a, G. A g r e, G. A n g e lov a. Trends and Opportunities in Computer Science OER Development. - Cybernetics and Information Technologies, Vol. 15, 2015, No 3, pp. 114-126.

91. T orre s, V. P. Development of Biofeedback Mechanisms in a Procedural Environment Using Biometric Sensors. MSc Thesis, Univ. of Porto, Portugal, 2013.

92. Toups, Z. O., R. Graeber, A. Kerne, L. Tas inary, S. Berry, K. Overby, M. Johnson. A Design for Using Physiological Signals to Affect Team Game Play. Foundations of Augmented Cognition, 2006, pp. 134-139.

93. O u m, K., H. A y a z, P. Shewokis, P. Di e f e $\mathrm{nb}$ a ch. MindTactics: A Brain Computer Interface Gaming Platform. - In: Proc. of ICE-GIC, Int. IEEE Consumer Electronics Society's, December 2010, pp. 1-5.

94. E m m e n, D. H. G., G. L a m p r o p o u 1 o s. BioPong: Adaptive Gaming Using Biofeedback. In: Proc. of Chi Sparks 2014 Conf., Hague, Netherlands, 3 April 2014, pp. 100-103.

95. B r a i th w a it e, J. J., D. G. W a t s o n, R. J o n e s, M. R o w e. A Guide for Analysing EDA\&Skin Conductance Responses for Psychological Experiments. - Psychophys., Vol. 49, 2013, pp. 1017-1034.

96. T i j s, T. J., D. B rokke n, W. A. I J s s e lste i j n. Dynamic Game Balancing by Recognizing Affect. - Fun and Games, LNCS, Vol. 5294, Berlin, Heidelberg, Springer, 2008, pp. 88-93.

97. Y annakakis, G. N., J. Hallam. Real-Time Game Adaptation for Optimizing Player Satisfaction. - IEEE Transactions on Comp. Intelligence and AI in Games, Vol. 1, 2009, No 2, pp. 121-133.

98. D i c h e v, C., D. D i c h e v a, G. A n g e l o v a, G. A g r e. From Gamification to Gameful Design and Gameful Experience in Learning. - Cybernetics and Information Technologies, Vol. 14, 2014, No 4, pp. 80-100. 